\title{
Chemical Modification of Hyaluronan and Their Biomedical Applications
}

\author{
Vera Hintze ${ }^{1 *}$, Matthias Schnabelrauch ${ }^{2 *}$ and Sandra Rother ${ }^{3 *}$ \\ ${ }^{1}$ Institute of Materials Science, Max Bergmann Center of Biomaterials, Technische Universität Dresden, Dresden, Germany, \\ ${ }^{2}$ Biomaterials Department, INNOVENT e. V., Jena, Germany, ${ }^{3}$ School of Medicine, Center for Molecular Signaling (PZMS), \\ Saarland University, Homburg, Germany
}

OPEN ACCESS

Edited by:

Jianrong Steve Zhou,

Peking University, China

Reviewed by:

Gloria Huerta-Angeles,

Contipro Inc., Czechia

Changchun Zhou,

Sichuan University, China

${ }^{*}$ Correspondence:

Vera Hintze

Vera.Hintze@tu-dresden.de

Matthias Schnabelrauch

ms@innovent-jena.de

Sandra Rother

sandra.rother@uks.eu

Specialty section:

This article was submitted to

Organic Chemistry,

a section of the journal

Frontiers in Chemistry

Received: 07 December 2021 Accepted: 10 January 2022

Published: 11 February 2022

Citation:

Hintze V, Schnabelrauch $M$ and Rother S (2022) Chemical Modification

of Hyaluronan and Their

Biomedical Applications.

Front. Chem. 10:830671.

doi: 10.3389/fchem.2022.830671
Hyaluronan, the extracellular matrix glycosaminoglycan, is an important structural component of many tissues playing a critical role in a variety of biological contexts. This makes hyaluronan, which can be biotechnologically produced in large scale, an attractive starting polymer for chemical modifications. This review provides a broad overview of different synthesis strategies used for modulating the biological as well as material properties of this polysaccharide. We discuss current advances and challenges of derivatization reactions targeting the primary and secondary hydroxyl groups or carboxylic acid groups and the $\mathrm{N}$-acetyl groups after deamidation. In addition, we give examples for approaches using hyaluronan as biomedical polymer matrix and consequences of chemical modifications on the interaction of hyaluronan with cells via receptormediated signaling. Collectively, hyaluronan derivatives play a significant role in biomedical research and applications indicating the great promise for future innovative therapies.

Keywords: hyaluronan, glycosaminoglycan, synthesis, interaction, signaling, degradation

\section{INTRODUCTION}

Hyaluronan (HA, formerly named hyaluronic acid) is an ionic, non-branched and multifunctional heteropolysaccharide. Together with other low- or medium-sulfated representatives (heparan sulfate, chondroitin sulfate, dermatan sulfate, keratan sulfate) and the high-sulfated heparin, the non-sulfated HA belongs to the family of naturally occurring glycosaminoglycan (GAG) biomacromolecules, the so called mucopolysaccharides. GAG are found throughout the body, often in mucus and joint fluids, and as components of the extracellular matrix (ECM) and tissues of vertebrates and invertebrates. GAG are localized also inside and on the surface of all cells. They are involved in various biochemical processes such as cell adhesion, growth and proliferation, cell surface binding, wound healing, or tumor metastasis (Dicker et al., 2014).

Compared to sulfated GAG, HA is a structurally uniform natural macromolecule and due to established biotechnological production processes it is readily available in higher quantities (Badri et al., 2018). Despite the progress achieved in the total synthesis of complex oligomeric carbohydrates (DeAngelis et al., 2013; Mende et al., 2016; Fittolani et al., 2021), HA represents an ideal starting material for the chemical conversion into other hardly accessible, mainly high-sulfated GAG or carbohydrate-analogous polymeric molecules mimicking their function, e.g., in the interactions with proteins like mediator molecules (e.g. cytokines).

There are two main features of HA that have contributed to its attractiveness as a biomaterial. Firstly HA can act as a passive structural molecule. Due to its macromolecular size, the marked hygroscopicity and viscoelasticity, $\mathrm{HA}$ is able to modulate tissue hydration, and to act as an osmotic 
balance. As a component of the ECM, HA can provide an extracellular space, where cells and various other ECM compounds like collagen or elastin fibers are firmly maintained. In an active way, $\mathrm{HA}$ is able to act as signaling molecule interacting with various receptor proteins, namely extracellular and cellular hyaloadherins (Fallacara et al., 2018). In this function HA is involved in angiogenesis, cell migration and motility, and tissue organization. It also plays a role in inflammation and stimulation of cytokine activity.

Secondly, HA can be functionalized and chemically modified to present a range of physical characteristics with wide-ranging solubility and even mechanical properties. HA is highly soluble in aqueous media, especially at low $\mathrm{pH}$, and it has a high rate of turnover in human tissue. At higher concentrations HA forms physically crosslinked gels of often unsatisfactory mechanical stability.

Both, the relatively rapid degradability of HA in living tissues and its low mechanical stability are often a challenge for the broad applicability of HA in the clinic as a versatile biomaterial. Classical applications of HA include currently injections into joint spaces for the treatment of osteoarthritis or into the eye to increase the viscosity of the vitreous humor as well as wound carrier materials based on HA-esters or crosslinked HA derivatives.

The synthesis of new HA derivatives should take into account the multifunctionality of the HA molecule by selecting highly regioselective syntheses applying mild reaction conditions. Special attention should also be paid to the properties of native $\mathrm{HA}$ as its excellent biocompatibility, adjustable biodegradability, and mucoadhesivity.

Based on the structural peculiarities and the multifunctional character of the high molecular-weight HA molecule, recent advancements in the selective chemical functionalization of HA are presented in the following. These selectively modified derivatives are intended, on the one hand, to mimic more complex GAG or GAG derivatives that can be synthesized only in time-consuming multi-step syntheses and high personal efforts. On the other hand, significant contributions to the detailed understanding of important interaction processes between GAG and their different reaction partners like ECM proteins, intracellular proteins or specific growth factors (Grosskopf et al., 2021) are expected.

\section{OCCURRENCE, BIOSYNTHESIS, AND DEGRADATION}

GAG occur as the constituents of so-called proteoglycans (all GAG members except HA) forming a large heterogeneous family of macromolecules consisting of a central protein backbone to which one or more unbranched GAG chains are covalently linked (Pomin and Mulloy, 2018). In case of cell surface proteoglycans, the protein core is membrane-spanning or lipid-bound, while ECM proteoglycans are predominantly secreted. HA is widely distributed in both prokaryotic and eukaryotic cells. Adult humans contain about $15 \mathrm{~g}$ of HA (Fallacara et al., 2018), mostly occurring in skin, vitreous body of the eye, umbilical
UDP-GICA + UDP-GIcNAC + (HA) $\stackrel{\text { HA synthase }}{\longrightarrow}(\mathrm{HA})_{n+1}+2$ UDP

FIGURE 1 | Overall reaction of the chain elongation step during HA biosynthesis.

cord, synovial fluid of articular joints, intervertebral disks, and embryonic mesenchymal tissues. In addition, it is present in further tissues such as heart valves, lungs, tendon sheaths, bursas aorta, and prostate (Valachová and Šoltés, 2021).

Biosynthesis of HA occurs in eukaryotic cells at the inner surface of the plasma membrane catalyzed by a class of integral membrane proteins, the HA synthases (HAS1, HAS2, HAS3; Vigetti et al., 2014). These enzymes which contain both GlcNAc $(\beta-1 \rightarrow 4)$ and GlcA $(\beta-1 \rightarrow 3)$ transferase activities, elongate HA at its reducing end by repeatedly adding nucleotide [uridinediphosphate (UDP)]-activated GlcA and UDP-GlcNAc to the nascent polysaccharide (Hascall and Esko, 2009). The overall reaction scheme is given in Figure $\mathbf{1}$ (Schnabelrauch et al., 2013). Finally, the synthesized HA is extruded through the plasma membrane into the extracellular space. A comparable pathway to produce $\mathrm{HA}$ is used by bacteria leading to HA with identical structural features (DeAngelis, 2012).

The first pharmaceutically pure HA was produced from rooster combs using the extraction and purification method by Balazs (Balazs, 1979). Currently, industrial production of HA mainly occurs by microbial fermentation (Boeriu et al., 2013) using at first Streptococci strains A and C, and more recently, various commercially available strains like Streptococcus equi, or Streptococcus zooepidemicus and even genetically modified bacterial strains (Moradali and Rehm, 2020; Manfrão-Netto et al., 2021). Even though high amounts of HA occur within the glycocalyx of all cells and in the ECM, the plasma HA levels are usually low due to the rapid clearance of HA in the kidney and liver (Fraser et al., 1997). About one-third of the total HA amounts in the human body are subject to daily turnover. HA degradation is mainly achieved by the activity of hyaluronidases, which catalyze the hydrolysis of disaccharides at hexosaminidic $(\beta-1 \rightarrow 4)$ linkages. In most tissues, among the six identified hyaluronidases, HYAL1 and HYAL2 are the dominating ones. Cell surface bound HYAL2 degrades high-molecular-weight HA into HA fragments of around 50 disaccharide units (about $20 \mathrm{kDa}$ ), which stimulate angiogenic and inflammatory signaling pathways (Stern, 2004). After internalization of these fragments into endosomes and transport to lysosomes, HYAL1 cleaves the HA fragments into small oligosaccharides before further degradation by exoglycosidases (Stern et al., 2006).

\section{GENERAL STRUCTURE AND PROPERTIES}

HA is a negatively charged, unbranched and multi-functional polysaccharide formed by repeating disaccharide units of $\mathrm{D}-\mathrm{N}$ acetylglucosamine (GlcNAc) and D-glucuronic acid (GlcA) linked by alternating $(\beta-1 \rightarrow 3)$ and $(\beta-1 \rightarrow 4)$ glycosidic bonds. In contrast to the other members of the GAG family, HA is not 


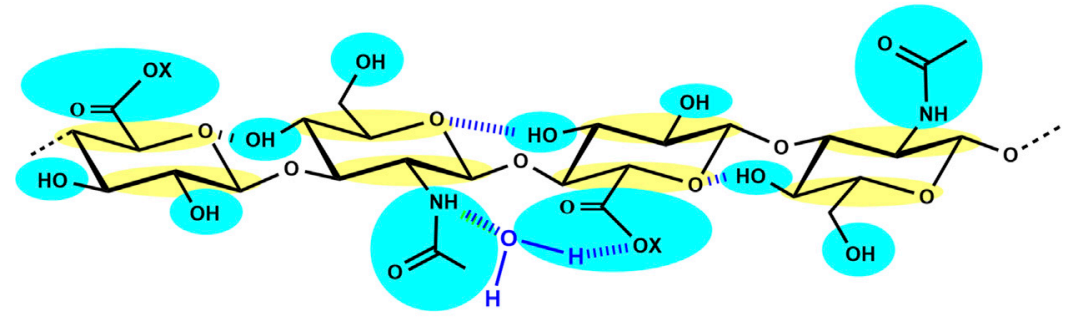

Hydrophilic unit Hydrophobic region

FIGURE 2 | HA tetrasaccharide unit schematically showing the hydrophilic moieties (in blue) and the hydrophobic regions (in yellow), while hydrogen bonds are represented by dark blue dashed lines (adapted from Fallacara et al., 2018, 10, 701).

sulfated. At physiological pH (around 7.4), most carboxyl groups are deprotonated and, therefore, $\mathrm{HA}(\mathrm{pK} \approx 3.2)$ is negatively charged. In solution and at physiological $\mathrm{pH}$ value, the negative charge of HA is balanced with different cations (e.g., $\mathrm{Na}^{+}, \mathrm{K}^{+}$, $\mathrm{Ca}^{2+}$, and $\left.\mathrm{Mg}^{2+}\right)$. Furthermore, HA can chelate and neutralize iron and copper ions, which are required for the Fenton reaction and are responsible to form the most deleterious reactive oxygen species (ROS) (Gligorovski et al., 2015). In the absence of iron and copper ions, the formation of these hydroxyl radicals is supressed. Moreover, HA can also neutralize ROS around leukocytes and protect neighboring cells (Litwiniuk et al., 2016).

Concluded from experimental findings and supported by various spectroscopic analyses and first data from energy calculations as well as computer simulations at the beginning of the 1990s, a twofold helix for HA was hypothesized to be present in aqueous solution (Heatley and Scott, 1988; Scott et al., 1991). The formed double helix is probably driven by interactions between large hydrophobic patches on alternate sides of the tapelike polymer and additionally by hydrogen bonding, forming stable aggregates at biological temperatures in water (Scott, 1992). This interplay of hydrophilic nature, hydrophobic portions, and a strong network of hydrogen bonds (Figure 2) results in the generation of an unstable $\beta$-sheet tertiary structure (Amorim et al., 2021). Although rather simply structured, compared to the other GAG, HA shows remarkable physico-chemical and biological properties (Bohaumilitzky et al., 2017). It is a very hygroscopic macromolecule able to tightly bind 15 water molecules per disaccharide repeating unit (Jouon et al., 1995) and has a great ability to retain water. Furthermore, HA shows a very high and shear-dependent viscoelasticity, resulting in the role of HA as an extracellular lubricant (Laurent et al., 1996). These remarkable hydrodynamic properties are essential for the biological function of HA to maintain tissue hydration, tension, and integrity.

The molecular weight of HA is a fundamental molecular parameter that has to be determined with high accuracy. Especially, the biological properties of HA and its synthesized derivatives largely depend on its molecular weight. Gel permeation chromatography (GPC), a special form of size exclusion chromatograpy (SEC), equipped with a multiangle laser light scattering (MALLS) detection system is the most commonly used analytical technique for determining the average molecular weight and molecular weight distribution (Botha et al., 2018; Schnabelrauch et al., 2021).

Depending on the biological source, HA may possess a very high molecular weight of about $10^{7}$ Dalton, e.g. as component in articular cartilage or of the synovial fluid in healthy joints (Fraser et al., 1997). In the physiological situation, there is a rapid HA turnover resulting in the constant presence of distinct forms of HA of various molecular weight (Bohaumilitzky et al., 2017). High-molecular weight HA (HMW-HA with molecular weights ranging from $1,000-5,000 \mathrm{kDa}$ ) possesses anti-inflammatory, anti-proliferative, anti-angiogenic, and immunosuppressive properties (Dovedytis et al., 2020). Besides providing water homeostasis, it modulates cell proliferation and differentiation, and participates in several other important biological processes, e.g. tissue regeneration, wound healing, epithelial integrity, embryogenesis, plasma protein distribution, and matrix structuring (Valachová and Šoltés, 2021).

\section{CHEMICAL MODIFICATION OF HA}

\section{General Remarks}

HA, like the other GAG, is a multifunctional macromolecule bearing primary and secondary hydroxyl, carboxyl, and $\mathrm{N}$-acetyl groups within each anhydrodisaccharide repeating unit and a reducing sugar end group at the HA chain terminus (Figure 3A). The carboxylate group is responsible for the anionic character of the polysaccharide and makes HA soluble in aqueous solutions. However, the presence of the ionic functionality in combination with an intra- and intermolecular hydrogen-bonding network makes HA insoluble in conventional organic solvents. Nevertheless, it is possible to transform the sodium salt or the acidic form of HA into tertiary or quaternary ammonium salts of HA rendering such salts soluble or at least highly swellable in aprotic solvents like N,N-dimethyl formamide (DMF) or dimethyl sulfoxide (DMSO). These solvents usually allow esterification reactions under nearly homogeneous reaction conditions (Moeller et al., 2012). Some other solvent systems like ionic liquids (Zakrzewska et al., 2010) have already been used to modify other non-GAG polysaccharides or have been used for 


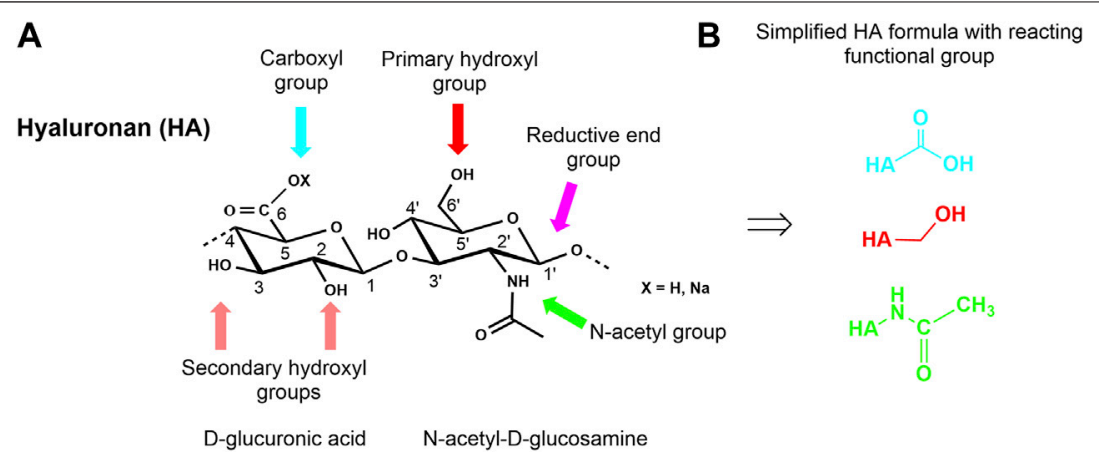

FIGURE 3 | Chemical structure of a HA disaccharide repeating unit showing the reactive functional groups (A) and presentation of simplified HA formulas with reaction centers involved in the different modifications (B).

the extraction of GAG- and ECM-containing proteins as supercritical carbon dioxide (Wang et al., 2017). Another aspect that must be considered when chemically manipulating HA and other GAG is their sensitivity to oxidative agents as well as to thermal stress.

Overall, the multi-functionality of HA (Figure 3B) combined with its limited solubility in organic solvents and its sensitivity to enzymatic and thermal degradation make the discovery of selective chemical reactions a challenge for the synthetic chemist.

In principle, HA can be modified by two different methods, crosslinking, and conjugation. Both methods are based on the same chemical reaction and differ in the fact that conjugation is characterized by grafting a single bond onto a HA chain whereas crosslinking means that different HA chains are linked together by two or more bonds (Schanté et al., 2011). Crosslinking is a well-known method to improve the mechanical, swelling, and rheological properties of HA. In this way, the degradation time of HA materials is slowed down and their residence time at the respective application site is enhanced. Covalent crosslinking provides the opportunity to provide hydrogels or cryogels, sponges, and other solid forms as scaffolds and drug carriers whilst maintaining biological functionality over an adjustable period of time (Williams, 2014).

Conjugation involves a variety of chemical modifications, such as the introduction of special functional units including ether, ester or amide groups, the attachment of bioactive as well as prodrug moieties, and last but not least the incorporation of marker molecules like specific dyes. Often an approach to chemically modify HA, contains both conjugation and crosslinking processes.

In recent years, the introduction of additional anionic groups, especially sulfate half-ester groups in $\mathrm{HA}$ has received much attention. Such highly-sulfated HA derivatives are able, similar to heparin and heparan sulfate, but in contrast to unsulfated HA, to interact with biological mediator molecules (e.g., growth factors) and positively influence biochemical processes, e.g. wound healing (for a detailed discussion, please see one of the next chapters on interaction of chemically modified HA with biological mediator proteins). Another example is the grafting of long hydrophobic chains onto HA. Amphiphilic HA polymers of this type can form strong physical interactions which are broken when submitted to high shear forces (HuinAmargier et al., 2005). Compared to native HA, the shearthinning behaviour of these HA derivatives is much more marked. An important property of native HA is its mucoadhesivity. Maintaining or improving mucoadhesive properties of HA derivatives is initially important for the development of effective drug release systems. Through thiolation of HA not only mucoadhesiveness can be improved, but also properties as swelling capacity, stability, enzyme inhibition properties, and biocompatibility can be enhanced (Griesser et al., 2018).

\section{Controlled Degradation to Provide Suitable Starting Hyaluronans for Chemical Modification}

The high solution viscosity of native $\mathrm{HA}$ in aqueous or organic solvents necessitates homogeneous reaction conditions as complete solubility and good miscibility. Therefore, the controlled degradation of HMW-HA to starting materials with molecular weights of $500-20 \mathrm{kDa}$ prior to chemical modification reactions might often be an advantage (Schnabelrauch et al., 2021). Retaining the original macromolecular structure in form of a degraded material free of undesired side products especially without non-saturated or oxidized moieties is essential. Further, there is another critical point concerning the degradation as well as the medical use of HA products. It is well accepted that HA can modulate many biological processes including cell adhesion, cell migration, morphogenesis, tumorigenesis, cell survival, apoptosis, and inflammation and that these biological effects can (and often do) differ depending on the HA molecular weight (Cyphert et al., 2015; Fallacara et al., 2018). The mentioned complications to ensure largely homogeneous chemical HA modifications and the increasing application of $\mathrm{HA}$ as a component of artificial matrices and in bioengineering for tissue scaffolding, makes it necessary to develop procedures leading to HA starting materials with a controlled range of molecular weight and a narrow dispersity.

In the human body the degradation of HA is either specifically mediated by a group of endoglycosidases, the so-called 


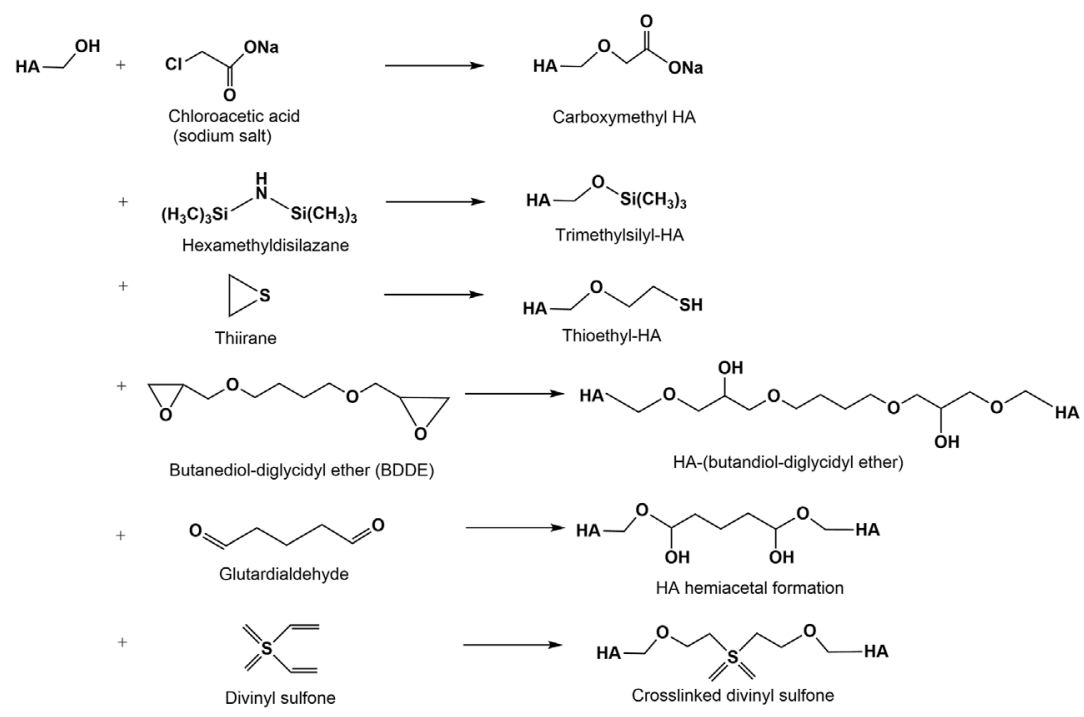

FIGURE 4 | Alkylation and bis-alkylation (crosslinking) of hydroxyl groups of HA.

hyaluronidases or non-specifically by oxidative damage due to initiation of reactive oxidative species (ROS) (Stern et al., 2007; Fallacara et al., 2018). In recent years, several enzymatic processes have been established to provide purified and structurally characterized HA oligosaccharides in up to milligram-/gram-scale quantities (Tawada et al., 2002; Blundell at al. 2006; Koehling et al., 2016). Degradation processes for HMW-HA have also been developed under largely controlled laboratory conditions by means of oxidative processes (Duan and Kasper, 2011). As oxidation agents mainly ozone (Yue 2012; Rother et al., 2015) or chlorine dioxide (Wyrwa et al., 2012) have been used. In recent years, intensive studies have been performed about acidic degradation of HA (Smejkalová et al., 2012a; Cozíková et al., 2017). Degraded HA with very narrow dispersity (Mw/Mn $<1.23$ ) covering a broad range of differently sized products $(420-3 \mathrm{kDa})$ could thus be obtained prior fractionation on a preparative scale. Based on earlier work on the thermal stability (Bothner et al., 1988; Lowry and Beavers, 1994), a simple thermal degradation process for HA was recently established (Kunze et al., 2010). Starting with a HA of weight-average molecular weight $\left(\mathrm{M}_{\mathrm{w}}\right)$ of $1,000 \mathrm{kDa}$ the final $\mathrm{M}_{\mathrm{w}}$-value of low molecular weight HA (LMW-HA) can be adjusted by choosing the processing time between 30 and $240 \mathrm{~min}$ resulting in $\mathrm{M}_{\mathrm{w}}$ from 500 to $6 \mathrm{kDa}$ (Schnabelrauch et al., 2021). Furthermore, automated solid-phase synthesis was used to produce HA oligosaccharides from monosaccharide building blocks, however, only in low amounts (Walvoort et al., 2012).

\section{Functionalization of the HA Hydroxyl Group}

\section{Alkylation Reactions}

The modification of hydroxyl group containing biopolymers with mono- and dialkylating agents to form ethers is a classical reaction for many polysaccharides (Heinze et al., 2018). In the
HA chemistry this reaction is especially used for crosslinking reactions resulting in hydrogels or scaffold materials (Figure 4). The synthesis of HA ethers is limited to a few examples due to harsh reaction conditions ( $\mathrm{pH} 13-14)$ often necessary for the etherification reaction. Water soluble alkyl derivatives of HA have been prepared by reaction of HA with 2-alkyloxymethyloxirane in DMSO under slightly alkaline conditions (Mlbochová et al., 2007). Another approach to HA ethers described the tosylation of the primary hydroxyl group of HA followed by exchange of the more reactive tosylate functionality by hydrophobic hexyl- and pentadecyl ether groups, resp. (Lapcik. et al., 2010). Carboxymethylated HA (CM-HA) can be synthesized in analogy to other carboxymethylated polysaccharides (Yang et al., 2010) by reacting HA with monochloroacetic acid under alkaline conditions (Moeller et al., 2012). Degrees of carboxymethylation $\left(\mathrm{DS}_{\mathrm{CM}}\right)$ for HMW- and LMW-HA ranging between 0.2 and 0.5 are obtained after a single carboxymethylation step. A repeated carboxymethylation gave a slight increase of the $\mathrm{DS}_{\mathrm{CM}}$-values to about 0.6-0.8. As shown by ${ }^{13} \mathrm{C}-\mathrm{NMR}$ studies, carboxymethylation mainly took place at the primary $\mathrm{OH}$-group of HA. Molecular weight determinations employed by GPC of the products confirmed a remarkable decrease after both alkylation steps. A thioethyl ether derivative was synthesized by reaction of ethylene sulfide (thiiran) to the hydroxyl groups of HA under alkaline conditions followed by addition of dithiothreitol (Serban et al., 2008). This derivative shows a radical scavenger activity.

Silylation of polysaccharides has been recognized as an effective method to prepare organic soluble derivatives and to improve their hydrophobicity (Heinze and Liebert, 2001). Silylation of HA has been reported to occur in a homogeneous salt complex of HA with cetyltrimethylammonium bromide (Scott, 1962). The silylation was performed in this salt complex homogenously using hexamethyldisilazane (HMDS) and DMSO as solvents (Zhang and James, 2005a) resulting in 
silylated HA materials characterized by high degree of substitution (DS) values (above 2.5), relatively low molecular weight loss, and solubility in non-polar organic solvents. Furthermore, the silylated cetyltrimethylammonium HA can be used as intermediate in an exchange reaction with aliphatic acid chloride (from hexanoyl to stearoyl acid chloride) to prepare HA esters (Zhang and James, 2005b). Trimethylsilyl chloride is formed as leaving group. The HA esters are soluble in non-polar solvents like xylenes.

Several difunctional agents have been used to crosslink hydroxyl groups of HA via ether linkages (Figure 4) forming hydrogels (Schanté et al., 2011; Collins and Birkinshaw, 2013; Khunmanee et al., 2017). Among diepoxy compounds used for the crosslinking of HA are butanedioldiglycidyl ether (Xue et al., 2020), ethylene glycol-diglycidyl ether (Oelschlaeger et al., 2016), polyethylene glycol diglycidyl ether (Calles et al., 2013), polyglycerol polyglycidyl ether (Yui et al., 1992) and 1,2,7,8 diepoxyoctane (Zhao, 2006). At present, BDDE represents the most promising diepoxide due to its easy availability and the capability to degrade into non-cytotoxic fragments (De Boulle et al., 2013). Numerous studies showed that crosslinking can be performed by hemiacetal bonds using glutardialdehyde in an acetonewater medium catalyzed at acidic conditions (Collins and Birkinshaw, 2007). However, under the same conditions, the hemiacetals can be hydrolyzed recovering the starting materials (Schanté et al., 2011). HA crosslinking is also performed with divinyl sulfone in alkaline solution (Collins and Birkinshaw, 2007; Shimojo et al., 2015).

\section{Esterification Reactions}

The esterification of the hydroxyl groups of HA is often a problem due to the incomplete solubility of HA in solvents suitable for acylation reactions and the lower reactivity of the secondary hydroxyl groups. Often more drastic conditions with regard to increased reaction temperature and time are needed, and in many cases only the primary hydroxyl groups are involved into the reaction. This was documented in earlier experiments on the esterification of HA with fatty acid chlorides in DMF/pyridine (Kawaguchi et al., 1992; Kawaguchi et al., 1995). In a later study HA was esterified with hexanoic anhydride under homogeneous reaction conditions at room temperature for $2 \mathrm{~h}$ (Smejkalová et al., $2012 b$ ). For this reason, the sodium salt of HA was previously converted into the acid form to perform the acylation in a completely dissolved state. Under the same reaction conditions, the sodium salt was esterified in a DMSO/water solution. The formed HA esters were elucidated by means of nuclear magnetic resonance (NMR) spectroscopy, and mass spectrometry. It was found that acylation in DMSO regioselectively took place at the primary hydroxyl group of the C-6 position whereas acylation in a DMSO/water solvent was carried out both at the primary C- 6 position, but also at the secondary hydroxyl group of the C-4 position of the N-acetylD-glucosamine unit.

The anhydrides of haloacetic acids have also been used to prepare bromo- and iodoacetates of HA which are versatile precursors for the formation of HA-based hydrogels (Serban and Prestwich, 2008).

In further studies, often highly reactive acylation components like imidazole-conjugated acids (Picotti et al., 2013) or mixed anhydrides (Huerta-Angeles et al., 2014) have been used as reactive intermediates. In a similar manner, it was also possible to graft acid-activated synthetic oligo-esters derived from polylactides and poly (3hydroxyalkanoates), resp., to the primary hydroxyl group of HA (Pravata et al., 2008; Huerta-Angeles et al., 2017). In a simple approach using an octenyl succinate half-ester as
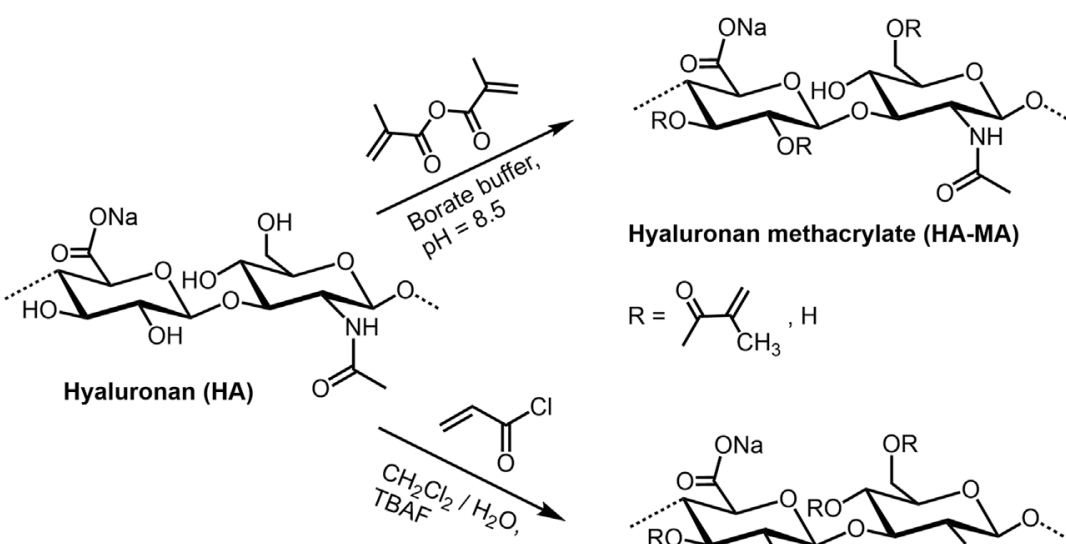

Hyaluronan methacrylate (HA-MA)<smiles>[R]=C(C)C(=C)C</smiles>

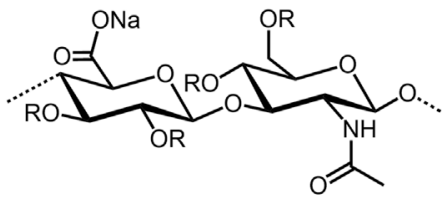

Hyaluronan acrylate (HA-AC)

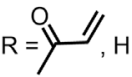

FIGURE 5 | (Meth)acrylation of HA 
reactive acylating reagent, an amphiphilic HA could be synthesized in aqueous media (Eenschooten et al., 2010).

Unsaturated HA esters serve as promising building blocks for the generation of novel supramolecular hydrogel networks with potential applications in regenerative, cell-based research and therapies (Highley et al., 2016; D’Amora et al., 2019; Kotla et al., 2021).

HA (meth)acrylates (Figure 5) are versatile macromers to generate functional coatings, and photopolymerizable scaffolds (Schnabelrauch et al., 2021). They can be prepared in a classical way by reaction of HA with methacrylic anhydride under $\mathrm{pH}$ values of 8-11 and ice cooling (Smeds et al., 2001; Burdick et al., 2005; Seidlits and al., 2010). The corresponding HA acrylate could be synthesized with acryolyl chloride both as mentioned above in a dichloromethane/water mixture (Qin et al., 2014), and with addition of tetra-n-butylammonium fluoride as phasetransfer catalyst (Becher et al., 2013). In analogy to nonderivatized HA, the sulfated derivatives with different degree of sulfation (DS: 0.9-1.4) can be (meth)acrylated in the same manner (Rother et al., 2017a). Further, HA esters of unsaturated carboxylic acids as pentenoates (Mergy et al., 2012) and maleates (Vasi et al., 2014) are available by treating HA with the corresponding acid anhydrides (see for example Smejkalova et al., 2014). A series of HA vinyl esters, able to be microstructured by two-photon lithography, have been synthesized by lipase-catalyzed transesterification (Qin et al., 2014).

\section{Sulfate and Phosphate Esters}

The biological properties of sulfated GAG are influenced to a considerable extent by the degree of sulfation and the sulfate group distribution within the disaccharide repeating units. In particular, the higher sulfated GAG can only be isolated to a limited extent with structural uniformity from biological sources and they are accessible by total synthesis only at extremely high time expenditure. For this reason, the stepwise and regioselective sulfation of $\mathrm{HA}$ is a time- and cost-efficient approach mimicking important biological features of high-sulfated GAG (Scharnweber et al., 2015; Townley and Bülow, 2018).

Experiments on the sulfation of HA were already carried out in the 1950s (Balazs et al., 1951). In these early experiments, sulfuric acid or chlorosulfonic acid were used as sulfating agents (Bedini et al., 2017; Caputo et al., 2019). These relatively drastic reaction conditions did not result in a complete sulfation of all free $\mathrm{OH}$ groups but caused a partial degradation of the polymer chain. Therefore, in more recent attempts, complexes of $\mathrm{SO}_{3}$ with organic amines, especially triethylamine (Satoh et al., 2004), trimethylamine (Nagira et al., 2007), and pyridine (Magnani et al., 1996) or amides like DMF (Crescenzi et al., 2002a) were used. The $\mathrm{SO}_{3}$-complexes are relatively mild reagents causing less polymer degradation. Due to their different reactivities in aprotic solvents, the sulfation of HA and other GAG is adjustable to a range between 0 and 4 . Preferentially, the sulfation is performed in aprotic solvents like DMF after transformation of HA in its tributyl ammonium salt (Magnani et al., 1998, Figure 6). Studies on regioselectivity of this reaction proved that the primary hydroxyl group reacts preferably. As shown by ${ }^{13} \mathrm{C}-\mathrm{NMR}$, a sulfation of secondary hydroxyl groups was detected in HA sulfates only at a degree of sulfation $\left(\mathrm{DS}_{\mathrm{S}}\right.$ ) above 1.0 (Hintze et al., 2009). In addition to regioselective sulfation reactions, there exist two other pathways for directing sulfate groups into specific positions of HA hydroxyl moieties, namely 1) de-sulfation reactions and 2) the use of protecting groups (Bedini et al., 2016; Bedini et al., 2017). Following the former route, desulfation of a high-sulfated $\mathrm{HA}\left(\mathrm{DS}_{\mathrm{S}}=3.1\right)$ by means of silylating agents like $\mathrm{N}$-methyl-N-(trimethylsilyl)trifluoroacetamide (MSTFA) or N,O-bis(trimethylsilyl) acetamide (BTSA) resulted in HA sulfates with $\mathrm{DS}_{\mathrm{S}}$ values of 1.5 and 1.6, resp., bearing the sulfate groups mainly at the secondary hydroxyl groups as shown by ${ }^{13} \mathrm{C}-\mathrm{NMR}$ (Becher et al., 2010). In this context, it was found that the benzoyl ester group is suitable to protect the primary hydroxyl group of HA and subsequent sulfation leads to a sulfated benzoylated HA (Becher et al., 2010). Cleavage of the benzoate group under mild alkaline conditions resulted in a HA sulfate with $\mathrm{DS}_{\mathrm{S}}$ values
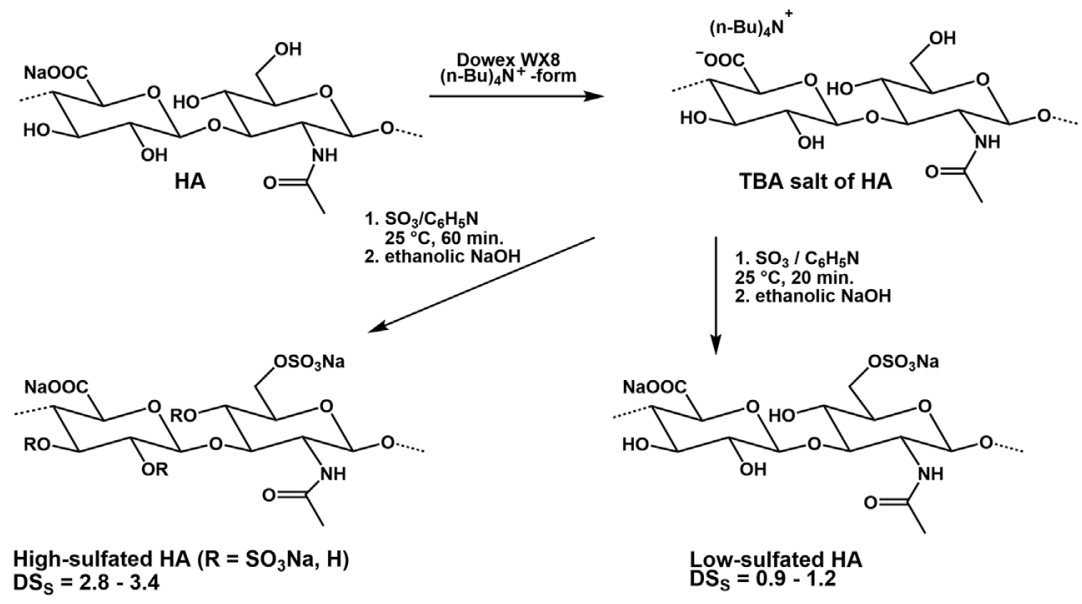

High-sulfated
$\mathrm{DS}_{\mathrm{S}}=2.8-3.4$

Low-sulfated HA
DS $_{\mathrm{S}}=0.9-1.2$

FIGURE 6 | Synthesis of high- and low-sulfated HA. 


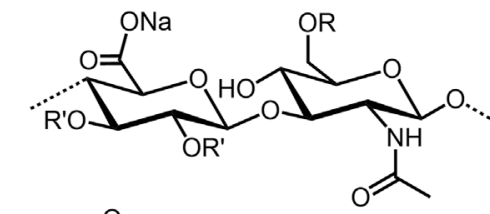

$\mathrm{MA}=$<smiles>C=C(C)C(C)=O</smiles>

Hyaluronan sulfate methacrylate (sHA1-MA)

$\mathrm{R}=\mathrm{SO}_{3} \mathrm{Na},\left(\mathrm{DS}_{\mathrm{S}}: 0.9-1.0\right)$

$R^{\prime}=M A, H,\left(D S_{M A}: 0.1-0.5\right)$

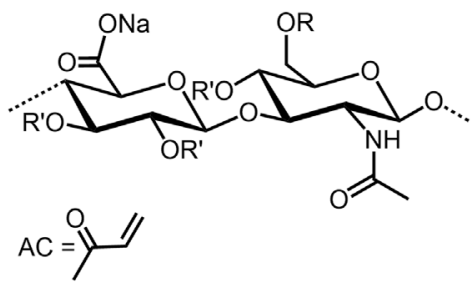

Hyaluronan sulfate acrylate
$\mathrm{R}=\mathrm{SO}_{3} \mathrm{Na}\left(\mathrm{DS}_{\mathrm{S}}: 0.9-1.0\right)$
$\mathrm{R}^{\prime}=\mathrm{AC}, \mathrm{H}\left(\mathrm{DS}_{\mathrm{AC}}: 0.1-0.5\right)$
$($ sHA1-AC)
$\mathrm{R}=\mathrm{AC}, \mathrm{H}\left(\mathrm{DS}_{\mathrm{AC}}: 0.1-0.5\right)$
$\mathrm{R}^{\prime}=\mathrm{SO}_{3} \mathrm{Na}, \mathrm{H}\left(\mathrm{DS}_{\mathrm{S}}: 1.0-1.4\right)$
(sHA1 $\triangle 6 \mathrm{~S}-\mathrm{AC})$

FIGURE 7 | Sulfated methacrylates, and sulfated acrylates of HA.

between 2.0 and 3.0. ${ }^{13} \mathrm{C}-\mathrm{NMR}$ confirmed a complete sulfation of the secondary hydroxyl groups and a free primary hydroxyl group. A subsequent esterification of the differently sulfated HA, for example, with (meth)acrylate groups result in mixed HA derivatives bearing both sulfate and (meth)acrylate units in different positions of the disaccharide repeating unit (Rother et al., 2017a; Becher et al, 2012, Figure 7). The introduction of a phosphate group into HA could be attractive for their application to biochemical systems via mediation of GAG-protein interactions. Although the phosphorylation of polysaccharides is reported in several reviews (Xu et al., 2019; Zhou and Huang, 2021), only few studies describe the phosphorylation of HA and give detailed characterization data of synthesized HA phosphates (Dulong et al., 2004; Leone et al., 2012; Bojarski et al., 2019). Phosphorylation is associated with several challenges that have not yet been satisfactorily solved. For example, the reactivity of conventional phosphorylating agents is significantly lower compared to sulfating agents, which requires harsher reaction conditions. At the same time, the tendency to crosslinking is much more pronounced with phosphorylation than with sulfation and hinders homogeneous reaction control. Chemical phosphorylation of HA and other GAG remains a challenge for the preparative polysaccharide chemistry.

\section{Oxidation}

Common oxidation reactions of polysaccharides have recently been reviewed (Palhares et al., 2021). The periodate oxidation, also called Malaprade oxidation acting on cis-diols which changes the polysaccharide backbone, and leads to the cleavage of the sugar ring forming corresponding carbonyl moieties (Kristiansen et al., 2010, Figure 8). Another typical regioselective oxidation of the primary hydroxyl group is mediated by the 2,2,6,6-tetramethyl-piperidinyl-1-oxy radical (Crescenzi et al., 2001; Pierre et al., 2017). The secondary hydroxyl groups and hence the sugar ring form are left unaffected. The actual oxidant in this reaction is the nitroxyl radical in form of a nitrosonium cation, which is continuously regenerated by another oxidant present in the reaction mixture. The oxidation can thus proceed to a high yield with only a catalytic amount of TEMPO (Jiang et al., 2000). In an improved

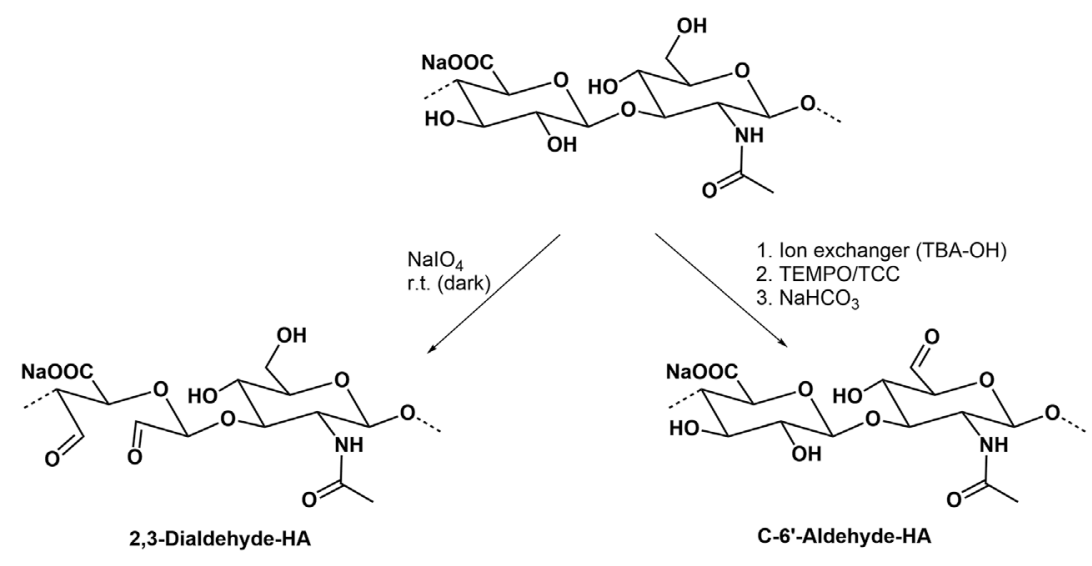

FIGURE 8 | Selective oxidation of hydroxyl groups of HA. 


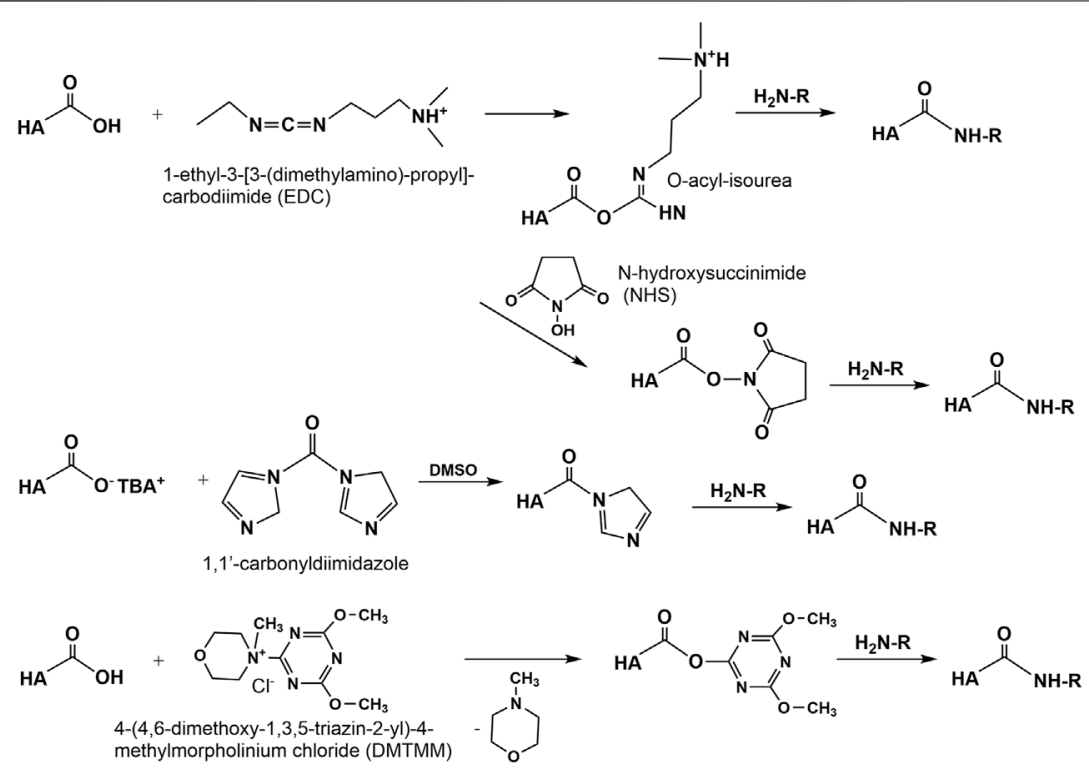

FIGURE 9 | Activation of the HA carboxyl group to perform HA amidation.

version, trichloroisocyanuric acid (TCC) is used as a secondary oxidation reagent (Figure 8), both to activate and regenerate TEMPO (Shan et al., 2021). Oxidized HA derivatives resulting from both types of oxidation can serve as precursors for the formation of drug releasing hydrogels (Zhang et al., 2011) or the conjugation of proteins (Mero and Campisi, 2014).

Besides TEMPO, also periodinane (also called Dess-Martin periodinane) can be used as a relatively mild oxidation agent which similar to TEMPO is able to transform primary hydroxyl groups from HA to aldehyde functions (Durana et al., 2006; Šedová et al., 2013). Aldehyde-containing HA derivatives have recently shown a high potential to prepare conjugates with different amines in drug delivery (Buffa et al. 2018).

\section{Functionalization of the HA Carboxyl Group}

\section{Esterification}

Strategies for the modification of the carboxyl group of HA also involve esterification and amidation reactions. Well-known biomaterials synthesized in this context are the family of HYAFF materials, especially the benzyl (HYAFF 11) and the ethyl ester (HYAFF 7) of HA (Benedetti et al., 1990; Benedetti et al., 1993). The HA esters have been prepared from the

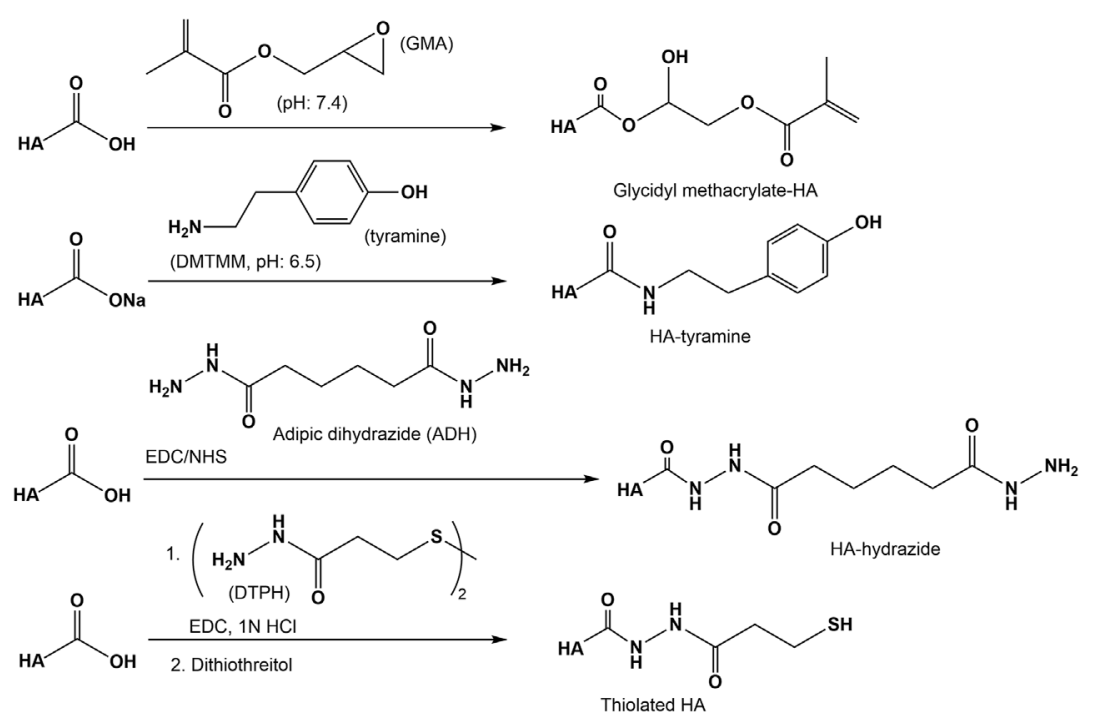

FIGURE 10 | Reactions of the HA carboxyl group with epoxides, amines, and hydrazides. 
corresponding alcohols after dissolution of the quaternary HA in an aprotic solvent (Campoccia et al., 1998).

The reaction of epoxides with the carboxyl group of HA is in particular reported for the reaction with glycidyl methacrylate to generate methacrylate ester under aqueous conditions with catalytic amounts of triethylamine (Baier Leach et al., 2003; Moeller et al., 2007). As shown by ${ }^{13} \mathrm{C}-\mathrm{NMR}$ studies (Bencherif et al., 2008) at $\mathrm{pH} 7.4$ two reactions occur simultaneously, namely an irreversible ring-opening conjugation through the HA carboxylic group toward the highest substituted carbon of the epoxide and a reversible transesterification through the primary hydroxyl group of HA.

\section{Amidation}

Amidation of the carboxyl group of HA with amines, hydrazins, and hydrazides is one of the most widely used method in the synthesis of new HA amides (Schanté et al., 2011), the design of novel delivery systems (Oh et al., 2010), and also in HA carboxybased network formation (Burdick and Prestwich, 2011). To initiate amidation, normally the carboxyl group of HA has to be activated. Typical activation agents used are water-soluble carbodiimides like 1-ethyl-3-[3-(dimethylamino)-propyl]carbodiimide (EDC), often used in combination with 1hydroxybenzotriazole (HOBt) or N-hydroxysulfosuccinimide (sulfo-NHS) (Bulpitt and Aeschlimann, 1999). Further activating agents are $1,1^{\prime}$-carbonyldiimidazole (D'Este et al., 2012), 2-chloro-1-methylpyridinium iodide (Magnani et al., 2000), 2-chloro-dimethoxy-1,3,5-triazine (Bergman et al., 2007), and 4-(4,6-dimethoxy-1,3,5-triazin-2-yl)-4methylmorpholinium chloride (D’ Este et al., 2014, Figure 9). The advantages of DMTMM conjugation, as a powerful tool to synthesize tyramine modified HA hydrogels, which are bioorthogonally crosslinked with horseradish peroxidase (HRP) and hydrogen peroxide $\left(\mathrm{H}_{2} \mathrm{O}_{2}\right)$ have also been demonstrated (Loebel et al., 2015).

A versatile chemical methodology that allows attachment of therapeutic drugs, reporter groups, crosslinking units, and other bioactive moieties to HA was developed in the Prestwich lab. Several mono-, bis-, and polyhydrazides have been attached at $\mathrm{pH}$ 4.0-4.75 in the presence of a water-soluble carbodiimide (EDC) to HA (Prestwich et al., 1998). Under similar conditions dithiocontaining hydrazides like 3,3'-dithiobis (propanoic hydrazide) (DTP) were attached to the carboxylic HA group (Shu et al., 2002, Figure 10). In the subsequent reaction step, the corresponding HA thiols are formed by addition of DTT. This disulfide crosslinked HA hydrogel can be prepared under physiological conditions without the addition of cross-linking agents and without the production of byproducts.

Another approach to attach thiol groups to HA consist in the reaction of the HA carboxyl group with cystamine in the presence of EDC/NHS at $\mathrm{pH} 4-5$ followed by cleavage of the disulfide using DTT (Jin et al., 2010, Figure 10). Using this method, also cysteine was attached via an amide linkage to the HA carboxyl group (Kafedjiiski et al., 2007). As recently shown, such thiolated HA derivatives are known for their mucoadhesive properties as well as enzyme inhibitory, permeation enhancing effects in drug delivery systems (Griesser et al., 2018).
Recently, a disulfide-based protecting group strategy for in situ formation of stable HA hydrogels has been developed (Ossipov et al., 2010). In this work a central divalent protecting group, $2,2^{\prime}$ dithiobis (ethoxycarbonyl), which links two identical molecules, was used. The designed reagents allow mild and highly controlled functionalization of $\mathrm{HA}$ with various types of nucleophilic chemoselective groups (Ossipov et al., 2010). The used strategy has been applied in later studies for the preparation of in situ forming HA gels hybridized with nanoparticles (Kheirabadi et al., 2015) or interpenetrating double HA-fibrin networks as an injectable and biodegradable scaffold for cell proliferation and differentiation (Zhang et al., 2016).

\section{Modification of the N-Acetyl Group of HA}

Deacetylation recovering the free amino group is the main reaction type performed at the $\mathrm{N}$-acetyl group of $\mathrm{HA}$ (Sedláček et al., 2020). Usually, deacetylation of HA occurs with hydrazine sulfate at increased temperatures over several days (Dahl et al., 1988; Crescenzi et al., 2002b). Recently, an advanced procedure, using a hydrazine/hydrazine sulfate mixture for deacetylation followed by the addition of iodic acid was described (Zhang et al., 2013; Babasola et al., 2014, Figure 11). In addition, partial deacetylation is also possible by treatment of HA with $\mathrm{NaOH}$ (Wada et al., 1994). In all these cases a substantial molecular weight decrease occurs. In contrast to chemical methods of $\mathrm{N}$-deacetylation, enzymatic processes of N-deacetylation (Chen et al., 2009; Kim and Kim, 2011) occur at mild conditions without massive molecular weight changes (Sedláček et al., 2020). However, this process requires enzymes (HA-N-deacetylases) which are at present not well described and commercially not available. Future progress in enzyme technology will help to prepare deacetylated HA without using hazardous and HA degrading chemicals. Several subsequent reactions of the amino group of deacetylated HA including reacylation (Babasola et al., 2014) or Ugi-reaction to form novel HA derivatives and hydrogels (Crescenzi et al., 2002b) have been described.

\section{Conjugation of HA by Reducing End Group Functionalization}

Advanced screening applications e.g., as microarrays, functional molecular and cellular assays, as well as biosensors require the attachment of HA to surfaces or other biomaterial scaffolds. In this regard, specific conjugation of active molecules like markers through the reducing end is desirable, as it effectively mimics the cell surface presentation of HA motifs and avoids alteration of HA-peptide interactions by chemical modifications along the biopolymer chain, or by surface-imposed conformational or spatial constraints. The most frequently used techniques for this type of GAG functionalization are currently hydrazone (Altgärde et al., 2013; Peerboom et al., 2017) and oxime (Novoa-Carballal and Müller, 2012; Thakar et al., 2014) ligation chemistry. Another procedure uses reductive amination with e.g., ethylendiamine dihydrochloride and sodium cyanoborohydride (Clauder et al., 2020). Examples of conjugation reactions are presented in Figure 12. 

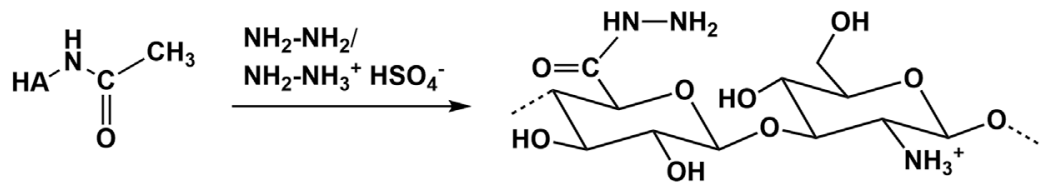<smiles>[R]C(=O)N[13CH3]</smiles>

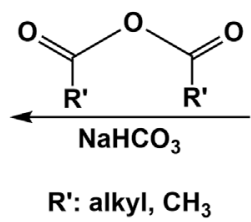

Re-acetylated HA

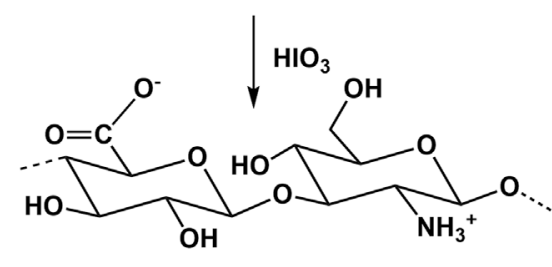

Deacetylated HA

FIGURE 11 | Deacetylation of HA with hydrazine.

HA functionalization at the reducing end can also be performed with a thiol group, enabling direct immobilization on gold and other metal surfaces and coupling to marker molecules as biotin. The end group functionalization is performed treating HA with cysteamine and using sodium cyanoborohydride as reductive agent (Minsky et al., 2016).

\section{Interaction of Chemically Modified Hyaluronan With Biological Mediator Proteins}

The interaction analyses of sulfated and carboxymethylated GAG derivatives with the biological mediator proteins transforming growth factor- $\beta 1$ (TGF- $\beta 1$ ), bone morphogenetic protein-2 and -4 (BMP-2 and -4) and osteoprotegerin (OPG) were previously reviewed (Schnabelrauch et al., 2013; Scharnweber et al., 2015) and are briefly summarized here. For these interactions, sulfation degree and patterns as well as the structure of the sugar backbone were identified as major determinants for binding strength as revealed by combining immunobiochemical methods and surface plasmon resonance (SPR) with molecular modelling (Hintze et al., 2009; Hintze et al., 2012; Salbach-Hirsch et al., 2013; Hintze et al., 2014). Using the complementary experimental methods, ELISA and SPR, with either the GAG or the proteins immobilized it could be shown that the derived GAG binding profiles match in general, excluding effects due to immobilization of one interaction partner. HA derivatives were found to interact stronger than the corresponding CS derivatives with the same sulfation degree (Hintze et al., 2009; Hintze et al., 2012; Hintze et al., 2014). Since the natural CS used for sulfation contained $70 \%$ chondroitin-4sulfate and $30 \%$ chondroitin-6-sulfate, differences in the sulfation degree of the C-4 position, next to different geometries of the sugar backbone, were identified as possible reasons for this effect. Further, the additional carboxymethylation of the high-sulfated sHA3 was detrimental for the binding strength towards TGF- $\beta 1$, which was attributed to possible differences in the C- 4 and C- 6 sulfation due to carboxymethylation preceding the sulfation reaction (Hintze et al., 2012).
In case of BMP-2 and OPG the biological relevance of the GAG/mediator protein interaction was further investigated by including cell receptors or other natural interaction partners in the SPR interaction studies, i.e. BMP-2 receptor-IA/Fc chimera or receptor activator NF- $\kappa \mathrm{B}$ ligand (RANKL) (Salbach-Hirsch et al., 2013; Hintze et al., 2014). Here, the latter were immobilized on the sensor surface and studied for their interaction with the mediator proteins pre-incubated with HA derivatives. In both cases, this resulted in a concentration- and sulfation-dependent decrease of the binding response indicating that HA derivatives interfere with the complexation of these natural interaction partners and thus reduce the biological activity of the respective biological mediators. For OPG, SPR findings on the biological relevance were supported in a RANKL-induced in vitro osteoclastogenesis model demonstrating a rescued osteoclast formation after pre-incubation of OPG with sulfated GAG (Salbach-Hirsch et al., 2013). In both cases, the integration of computational methods revealed how sHA derivatives influence the interplay of these mediators with their natural interaction partners up to the atomic level.

This approach was subsequently applied on further biological systems to gain a broader understanding of the structure-function relationship of GAG in their interaction with mediator proteins relevant to the healing process in bone and skin and the biological consequences of these interactions.

The biological relevance of the GAG/TGF- $\beta 1$ interaction was further investigated by including its natural receptors TGF- $\beta$ receptor-I (T $\beta$ R-I) and -II (T $\beta$ R-II) (Koehler et al., 2017). As for BMP-2 and OPG, sHA blocked binding of TGF- $\beta 1$ to its receptors in a concentration- and sulfation-dependent manner, supporting a previous publication showing an impaired TGF- $\beta 1$ driven differentiation of dermal fibroblasts due to TGF- $\beta 1$ interaction with sHA derivatives (van der Smissen et al., 2013).

The capability of GAG derivatives to modulate canonical Wnt signaling, in particular the activity of the extracellular inhibitors sclerostin (SOST) and Dickkopf (Dkk-1) that promote osteoclastogenesis and bone resorption, was evaluated utilizing a combination of the abovementioned complementary methods 


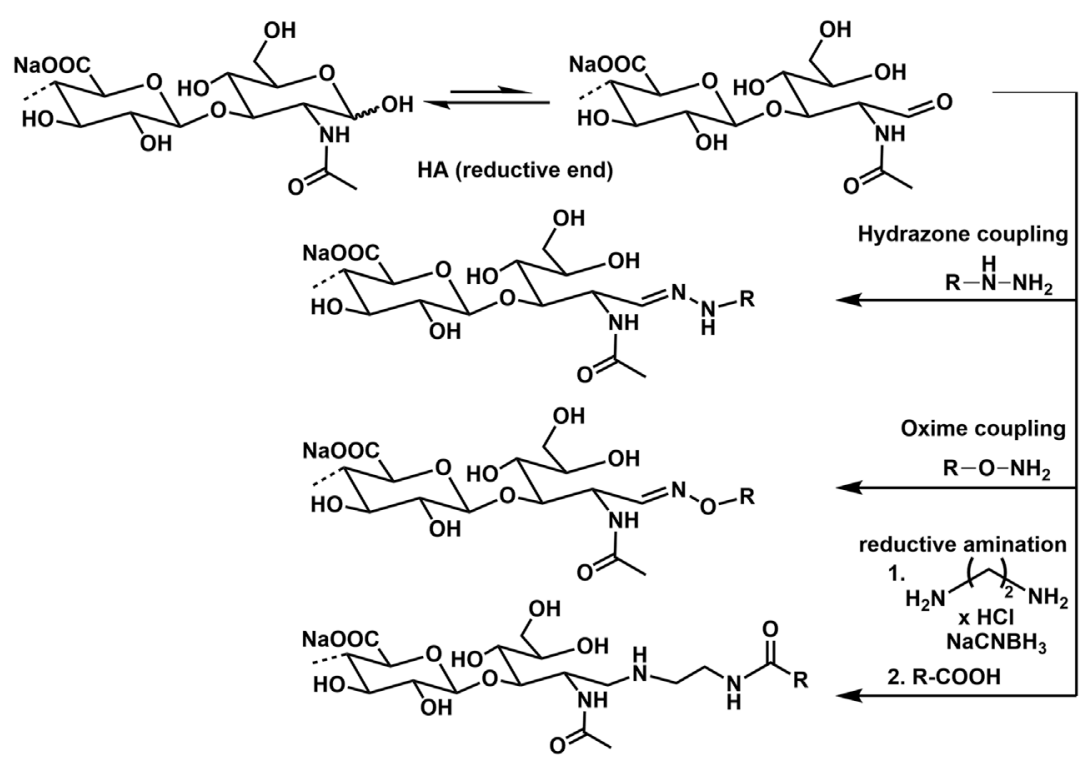

FIGURE 12 | Conjugation of amino group containing molecules at the reducing end of HA.

(Salbach-Hirsch et al., 2015; Gronbach et al., 2020). SPR revealed that GAG interact with SOST in a concentration- and sulfationdependent manner, with sHA3 being the strongest binder, while high-sulfated CS (sCS3) and heparin demonstrated significantly weaker binding (Salbach-Hirsch et al., 2015). In contrast, HA binding was found to be marginal. The biological relevance was verified in an LRP5/SOST interaction study and in an in vitro model of Wnt activation showing a sulfation- and concentrationdependent reduction in bioactivity due to the SOST/GAG interaction via interference with sclerostin/LRP5/6 complex formation.

The sulfation-dependent interaction of sHA3 with Dkk-1 was demonstrated by SPR analysis (Gronbach et al., 2020). Further, binding affinity was found to be comparable for those derivatives containing an ATTO-565 fluorescent label to non-labeled sHA3, while non-sulfated ATTO-labeled GAG showed negligible binding responses towards Dkk-1. This result was in line with findings of the same study on a macromer-based film covalently decorated with ATTO-labeled sHA3 efficiently scavenging Dkk-1 and displaying pro-osteogenic effects with SaOS-2 cells and primary human mesenchymal stem cells (hMSC).

The interaction of polymeric and oligomeric GAG derivatives with heparin-binding EGF-like growth factor (HB-EGF), a major factor activating keratinocytes and dermal fibroblasts in skin wound healing, was analyzed via SPR and molecular modeling (Thönes et al., 2019). While there was no binding detected for non-sulfated HA, CS and sHA1 were found to interact with HBEGF. Interestingly, heparin displayed the same binding strength as sHAl albeit a higher sulfation degree. This indicated that next to sulfation degree, the sulfation pattern and/or the structure of the sugar-backbone might play a role. This was supported by the interaction profiles of HA oligosaccharides with immobilized HB-EGF demonstrating an interaction for those molecules with at least one sulfate group at the $\mathrm{C} 4$ or $\mathrm{C} 6$ position of the
$\mathrm{N}$-acetylglucosamine unit. In this case, the binding strength of sHA tetrasaccharides increased with the degree of sulfation. Importantly, the interaction strength of a persulfated hexasaccharide was found to be lower than for its tetrasaccharide counterpart, highlighting an additional effect of chain length. These findings provided a rational for the development of sHA1-containing HA/collagen hydrogels that were found to improve wound healing processes in vitro and in a porcine skin organ culture model by the sustained release of biologically active HB-EGF.

A particular striking example of how biophysical/biochemical interaction analyses in combination with computational methods and in vitro cell culture models move forward insights into the mechanism of GAG action, are a compendium of studies regarding the tissue inhibitor of metalloproteinases-3 (TIMP-3). First of all, the molecular interplay of polymeric and oligomeric GAG derivatives with TIMP-3 was demonstrated by SPR, molecular modeling and hydrogen/deuterium exchange mass spectrometry (Rother et al., 2016a). Interestingly, unlike for previously investigated mediators, the interaction of sHA derivatives was found to be of comparable strength than for the corresponding sCS derivatives with the same sulfation degree. Importantly, this interaction did not limit the capacity of TIMP-3 to inhibit matrix metalloproteinase-1/-2 (MMP-1/-2) in enzyme kinetics, since no overlap of the binding sites was revealed. These observations pointed towards a novel strategy for controlling ECM remodelling by GAG, e.g. in chronic wound situations, via stabilizing and accruing TIMP-3, while maintaining its inhibitory activity towards MMP activity. This hypothesis was further corroborated by the observation that TIMP-3 directly interacts with clusters of the endocytic receptor low-density lipoprotein receptor-related protein (LRP-1) (Rother et al., 2016b; Figure 13A). GAG were shown to interfere with this TIMP-3/LRP-1 complex formation in a sulfation-dependent 

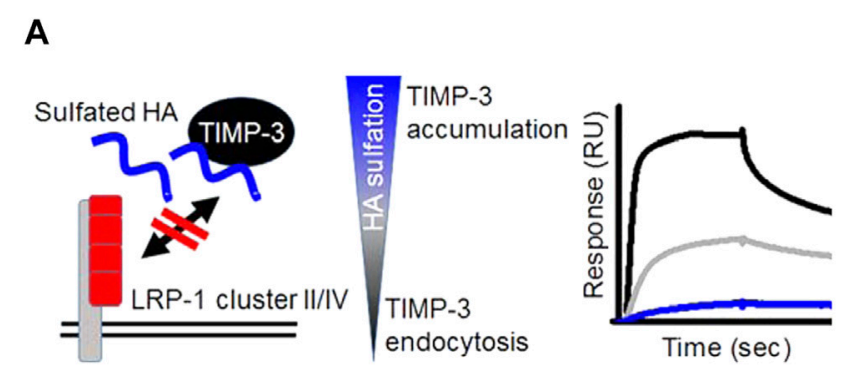

B

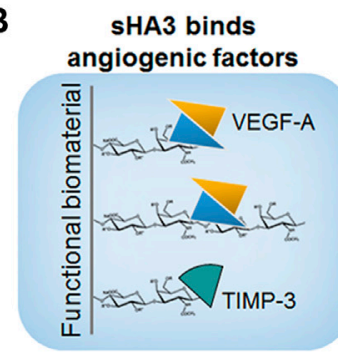

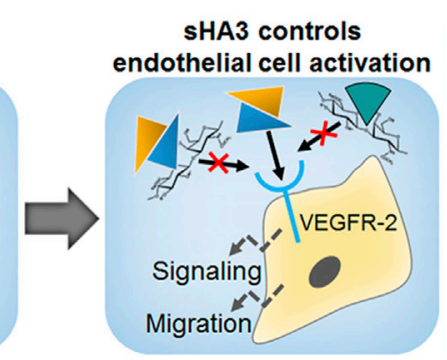

FIGURE 13 | Mechanisms of GAG action on TIMP-3. (A) GAG control ECM remodelling via stabilizing and accruing TIMP-3, interfering with TIMP/LRP-1 complex formation and increasing extracellular TIMP-3 level; SPR sensorgram: binding analysis of solute TIMP-3 with immobilized LRP-1 cluster II in the absence or presence of differently sulfated sHA (black line: interaction of TIMP-3 alone, grey and blue line: interaction with TIMP-3 after preincubation with sHA1 and sHA3, respectively). (B) GAG control endothelial cell activation by interfering with VEGFR-2 complexation via VEGF-A and TIMP- (Reprinted with permission from Rother S. et al. 2016 Biomacromolecules 17, 3252-3261 and Rother S. et al. 2017 ACS Appl. Mater. Interfaces 9, 9539-9550. Copyright ũ 2016/2017 American Chemical Society).

manner. Further, sHA1 was found to increase the extracellular TIMP-3 level of hMSC. Thus, sHA-containing biomaterials might be promising to interfere with pathological matrix degradation and thereby encourage wound healing. Finally, a novel mechanism was identified by which GAG might control angiogenic processes (Rother et al., 2017b; Figure 13B), which could be of interest in angiogenesis-related diseases. By blocking the binding of both, VEGF-A and the angiogenic inhibitor TIMP-3, to the VEGF-A receptor VEGFR-2, GAG reduce the biological activity in a sulfation-dependent manner. When TIMP-3/sHA complexes were simultaneously forming, VEGF-A/VEGFR-2 signaling was partially rescued. While labeling sHA3 with an ATTO-565 fluorescent label did not change the binding characteristics of sHA3 with immobilized Dkk-1 as mentioned above (Gronbach et al., 2020), acrylation significantly reduced binding strength of the low sulfated HA derivatives, sHA1 and sHA1 $\Delta 6$ s, towards immobilized VEGF-A in SPR analysis as well as in molecular docking and dynamics (MD) simulations (Rother et al., 2021). This was supported by a solid-phase binding assays with immobilized GAG demonstrating a significantly negative effect of acrylation for sHA1 $\Delta 6$ s suggesting that the presence of acrylate groups alter the accessibility of the sulfate groups and/or have a detrimental effect on the optimal carbohydrate conformation. When translated to sHA-containing acrylated $\mathrm{HA} /$ collagen hydrogels, this led to biomaterials releasing biologically active VEGF-A in a defined manner depending on the substitution pattern of the sulfated GAG. In turn angiogenic processes like endothelial cell proliferation and the formation of an extended morphology, indicating sprouting, could be controlled. Together with the findings of Thönes et al., it can be concluded that multivalent carbohydratebased hydrogels containing acrylated sHA derivatives are promising for reaching distinct growth factor delivery profiles, increasing the healing capacity of vascularized tissues.

\section{HA AS BIOMEDICAL POLYMER MATRIX}

Native HA is biofunctional and forms viscoelastic biocompatible and degradable polymer networks making it an interesting material for medical and pharmacological applications. However, modifying $\mathrm{HA}$ is especially favorable to overcome certain limitations of native HA such as the quick enzymatic degradation and rapid dissolution in water (Smejkalová et al., 2012b). A higher enzymatic resistance as well as tunable solvation profiles are often prerequisites for biomedical applications. The simplest usage of HA is in form of solutions in physiological buffers, where different properties are achieved by varying the concentration as well as the molecular weight of HA (Nicholls et al., 2018). Hybrid complexes composed of thermally treated HMW-HA and LMW-HA based on biophysical interactions between hydrogen bonds of $\mathrm{HA}$ chains are explored as injectable polymer matrix especially for the treatment of osteoarthritis (Stellavato et al., 2019; La Gatta et al., 2021).

Chemical modification strategies targeting the preponderantly present carboxylic acid groups, or primary and secondary hydroxyl groups and, after deamidation, the $\mathrm{N}$-acetyl groups, give rise to HA derivatives with altered biological as well as material properties (Figure 14). The introduction of hydrophobic groups allows to encapsulate for example, hydrophobic drugs in amphiphilic HA, which was used for active targeting and drug delivery (Smejkalová et al., 2012b; Huerta-Angeles et al., 2014; Kwag et al., 2014; Huerta-Angeles et al., 2016). Achieving tailored HA properties depends on precise and effective synthesis strategies. In this regard, functionalized HA can be used to generate films and hydrogels after crosslinking with different mechanical properties as sprays, wound dressings, scaffolds for tissue engineering approaches or as anti-adhesive materials (Eng et al., 2010; Gebe et al., 2017; reviewed in Burdick and Prestwich, 2011).

In addition, HA derivatives conjugated with metallic particles, like gold nano particles, are explored for targeted treatment of infected and cancer cells (Lee et al., 2012; Sanfilippo et al., 2020). HA-protein conjugates using for example, growth factors have been produced to mask the protein activity and to extend the protein stability (Ferguson et al., 2010; Altiok et al., 2016). Commercially available degradation assays use immobilized biotin-tagged $\mathrm{HA}$ as substrate to determine hyaluronidase activities (Krupkova et al., 2020). Another way to use HA for mimicking the native cell microenvironment is by physically 

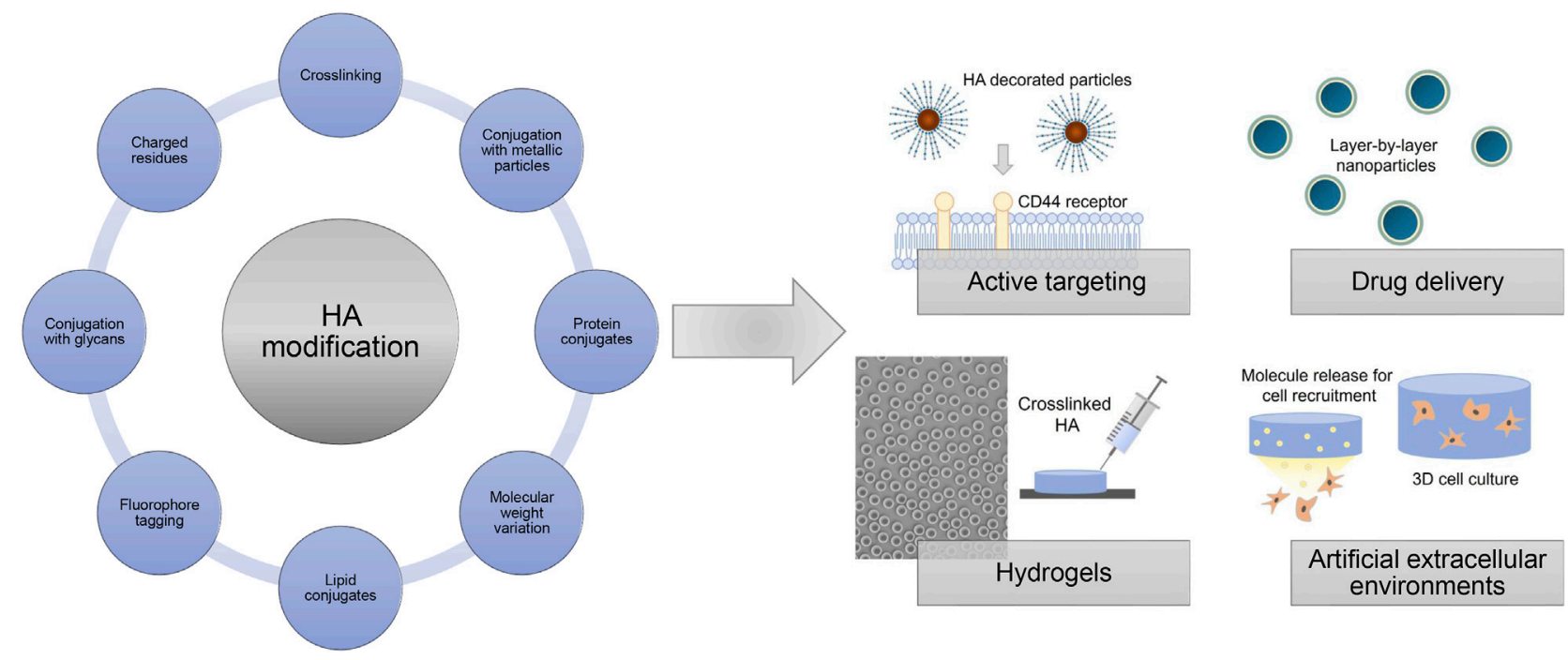

FIGURE 14 | Overview of HA modification strategies and selected applications.

entrapping HA of different molecular weights within a polymer network like collagen fibers (Rother et al., 2015; Unnikandam Veettil et al., 2021).

The negative charge of HA allows for non-specific adsorption on cationic surfaces such as poly (L-lysine)coated substrates and layer-by-layer approaches (Dreaden et al., 2014; Kocourková et al., 2021). Bisphosphonatefunctionalized HA was used as injectable non-covalently self-assembling hydrogel with reversible calcium binding properties (Nejadnik et al., 2014). Surfaces coated with HAbinding proteins like aggrecan globular domain 1 (HA binding protein, $\mathrm{HABP}$ ) or $\mathrm{HA}$ binding peptides allow for a more selective capturing of $\mathrm{HA}$, which can be used for potential interaction studies e.g. in form of enzyme-linked immunosorbent assays and GAG-protein microarrays (Yuan et al., 2013; Faust et al., 2018). HA derivatives with introduced negatively charged residues like sulfate groups and networks composed of HA covalently linked to sulfated GAG derivatives like chondroitin sulfate are also exploited as platforms with tunable growth factor presentation and release to direct cellular behavior ( $\mathrm{Ni}$ et al., 2015; Thönes et al., 2019). Furthermore, HA derivatives with covalently attached fluorophores are widely applied as tools studying the potential association and translocation of HA in biological contexts (AlKhoury et al., 2020). Overall, modified HA derivatives are widely used and explored in different biomedical fields and applications repeatedly indicating the great promise for future customized therapies.

Due to its transparency and its lubricating and hydrophilic properties, HA solutions are often used during ophthalmic surgery and for ophthalmic preparations such as eye drops treating the dry eye syndrome (Huerta Angeles and Nesporova, 2021). Furthermore, HA is widely applied as part of contact lenses, for surface modifications of medical lenses and for sustained drug release to treat eye-related diseases (Chang et al., 2021). Subcutaneous injections of HA solutions and in situ forming hydrogels are applied in aesthetic dermatology for reducing wrinkles, folds, and augmenting for example, lips (Rah, 2011). In addition, viscosupplementation with HA formulations is often used to treat osteoarthritis in the knee and in other joints by reducing the mechanical stress on the joints (Henrotin et al., 2015).

\section{PERSPECTIVES AND CONCLUDING REMARKS}

In the last decades, the development of $\mathrm{HA}$ as a biomaterial has been a major success due to the good industrial availability of pure HA and its properties including an excellent biocompatibility, an adjustable biodegradability, mucoadhesiveness and viscoelasticity.

This review aims to provide a short overview about known and suitable chemical methods to modify the natural GAG, HA, which is of particular interest in the field of tissue regeneration and regenerative medicine. Due to the mentioned challenges of limited HA solubility in organic solvents and its sensitivity to more drastic chemical reaction conditions with regard to oxidative or thermal stress, and both strong acidic or alkaline environment, the controlled chemical modification of this multifunctional polysaccharide is still a challenging task. Nevertheless, during the last decade, numerous regioselective syntheses routes could be elaborated, which proceed with high control of regioselectivity regarding the degree and the position of substitution along the $\mathrm{HA}$ chain as well as with largely preservation of the HA molecular weight. At last, this could also be achieved by the advancement of modern polymer analytics, especially high-resolution NMR-spectroscopy. A current trend is the combination of conjugation and crosslinking processes using bioactive molecules for applications in 
regenerative medicine, pharmaceuticals and bioengineering, including cell and bioactive molecule delivery combined with tissue engineering scaffolds (Knopf-Marques et al., 2016; Fallacara et al., 2017). Although HA displays a great number of potential applications, further studies and technological advancement are necessary as there are still some open questions to be answered. The key mechanisms that control the molecular weight of HA during biotechnological synthesis has to be clarified to develop methods for the production of defined HA with uniform size (Fallacara et al., 2018). Also the reproducibility of the preparation of HA derivatives during scaleup processes has to be improved as a basis for their successful commercialization.

A wide range of biological activities has been investigated using modified HA derivatives and some of these applications are highlighted in this paper. HA has a broad scientific capability and especially the role of sulfated HA in viral infections, and the potential of HA and other GAG to address numerous medical and biotechnological challenges is becoming without any doubt the focus of renewed attention.

\section{REFERENCES}

AlKhoury, H., Hautmann, A., Erdmann, F., Zhou, G., Stojanović, S., Najman, S., et al. (2020). Study on the Potential Mechanism of Anti-inflammatory Activity of Covalently Immobilized Hyaluronan and Heparin. J. Biomed. Mater. Res. A. 108, 1099-1111. doi:10.1002/jbm.a.36885

Altgärde, N., Nilebäck, E., de Battice, L., Pashkuleva, I., Reis, R. L., Becher, J., et al. (2013). Probing the Biofunctionality of Biotinylated Hyaluronan and Chondroitin Sulfate by Hyaluronidase Degradation and Aggrecan Interaction. Acta Biomater. 9, 8158-8166. doi:10.1016/j.actbio.2013.05.031

Altiok, E. I., Santiago-Ortiz, J. L., Svedlund, F. L., Zbinden, A., Jha, A. K., Bhatnagar, D., et al. (2016). Multivalent Hyaluronic Acid Bioconjugates Improve sFlt-1 Activity In Vitro. Biomaterials 93, 95-105. doi:10.1016/j.biomaterials.2016. 03.017

Amorim, S., Reis, C. A., Reis, R. L., and Pires, R. A. (2021). Extracellular Matrix Mimics Using Hyaluronan-Based Biomaterials. Trends Biotechnol. 39, 90-104. doi:10.1016/j.tibtech.2020.06.003

Babasola, O., Rees-Milton, K. J., Bebe, S., Wang, J., and Anastassiades, T. P. (2014). Chemically Modified N-Acylated Hyaluronan Fragments Modulate Proinflammatory Cytokine Production by Stimulated Human Macrophages. J. Biol. Chem. 289, 24779-24791. doi:10.1074/jbc.M113.515783

Badri, A., Asher Williams, A., Robert J Linhardt, R. J., and Koffas, M. A. G. (2018). The Road to Animal-free Glycosaminoglycan Production: Current Efforts and Bottlenecks. Curr. Opin. Biotechnol. 53, 85-92. doi:10.1016/j.copbio.2017.12.018

Baier Leach, J., Bivens, K. A., Patrick, C. W., Jr., and Schmidt, C. E. (2003). Photocrosslinked Hyaluronic Acid Hydrogels: Natural, Biodegradable Tissue Engineering Scaffolds. Biotechnol. Bioeng. 82, 578-589. doi:10.1002/bit.10605

Balazs, E. A. (1979). "Ultrapure Hyaluronic Acid and the Use There of". U.S. Patent No. 4,141,973,27.

Balazs, E. A., Högberg, B., and Laurent, T. C. (1951). The Biological Activity of Hyaluron Sulfuric Acid. Acta Physiol. Scand. 23, 168-178. doi:10.1111/j.17481716.1951.tb00806.x

Becher, J., Moeller, S., and Schnabelrauch, M. (2013). Phase Transfer-Catalyzed Synthesis of Highly Acrylated Hyaluronan. Carbohydr. Polym. 93, 438-441. doi:10.1016/j.carbpol.2012.12.056

Becher, J., Moeller, S., Weiss, D., Schiller, J., and Schnabelrauch, M. (2010). Synthesis of New Regioselectively Sulfated Hyaluronans for Biomedical Application. Macromol. Symp. 296, 446-452. doi:10.1002/masy.201051060

Becher, J., Möller, S., Riemer, T., Schiller, J., Hintze, V., Bierbaum, S., et al. (2012). Sulfated Glycosaminoglycan Building Blocks for the Design of Artificial

\section{AUTHOR CONTRIBUTIONS}

VH: Wrote the chapter "Interaction of Chemically Modified Hyaluronan With Biological Mediator Proteins," prepared the respective figure and revised the complete manuscript critically. SR: Wrote the abstract, the chapter "HA as Biomedical Polymer Matrix" and parts of "Occurrence, Biosynthesis, and Degradation, prepared the respective figure and revised the complete manuscript critically. MS: Wrote all other chapters of the manuscript, and prepared the respective figures. All authors substantially contributed to the conception of this review, and revised the complete manuscript critically. All authors agree to be accountable for the content of the work.

\section{FUNDING}

Authors VH and MS acknowledge funding by the Deutsche Forschungsgemeinschaft (DFG, project number 59307082TRR67, subprojects Z3, A3).

Extracellular Matrices. ACS Symp. Ser. 1107, 315-328. doi:10.1021/bk-20121107.ch017

Bedini, E., Laezza, A., and Iadonisi, A. (2016). Chemical Derivatization of Sulfated Glycosaminoglycans. Eur. J. Org. Chem. 2016, 3018-3042. doi:10.1002/ejoc. 201600108

Bedini, E., Laezza, A., Michelangelo Parrilli, M., and Iadonisi, A. (2017). A Review of Chemical Methods for the Selective Sulfation and Desulfation of Polysaccharides. Carbohydr. Polym. 174, 1224-1239. doi:10.1016/j.carbpol. 2017.07.017

Bencherif, S. A., Srinivasan, A., Horkay, F., Hollinger, Matyjaszewski, J. O. K., and Washburn, N. R. (2008). Influence of the Degree of Methacrylation on Hyaluronic Acid Hydrogels Properties. Biomaterials 29, 1739-1749. doi:10. 1016/j.biomaterials.2007.11.047

Benedetti, L., Cortivo, R., Berti, T., Berti, A., Pea, F., Mazzo, M., et al. (1993). Biocompatibility and Biodegradation of Different Hyaluronan Derivatives (Hyaff) Implanted in Rats. Biomaterials 14, 1154-1160. doi:10.1016/01429612(93)90160-4

Benedetti, L. M., Topp, E. M., and Stella, V. J. (1990). Microspheres of Hyaluronic Acid Esters - Fabrication Methods and In Vitro Hydrocortisone Release. J. Controlled Rel. 13, 33-41. doi:10.1016/0168-3659(90)90072-2

Bergman, K., Elvingson, C., Hilborn, J., Svensk, G., and Bowden, T. (2007). Hyaluronic Acid Derivatives Prepared in Aqueous Media by TriazineActivated Amidation. Biomacromolecules 8, 2190-2195. doi:10.1021/ bm0701604

Blundell, C. D., Michelle Reed, M. A. C., and Almond, A. (2006). Complete Assignment of Hyaluronan Oligosaccharides up to Hexasaccharides. Carbohydr. Res. 341, 2803-2815. doi:10.1016/j.carres.2006.09.023

Boeriu, C. G., Springer, J., Kooy, F. K., van den Broek, L. A. M., and Eggink, G. (2013). Production Methods for Hyaluronan. Int. J. Carbohydr. Chem. 2013, 624967. doi:10.1155/2013/624967

Bohaumilitzky, L., Huber, A.-K., Stork, E. M., Wengert, S., Woelfl, F., and Boehm, H. (2017). A Trickster in Disguise: Hyaluronan's Ambivalent Roles in the Matrix. Front. Oncol. 7, 242. doi:10.3389/fonc.2017.00242

Bojarski, K. K., Becher, J., Riemer, T., Lemmnitzer, K., Möller, S., Schiller, J., et al. (2019). Synthesis and In Silico Characterization of Artificially Phosphorylated Glycosaminoglycans. J. Mol. Struct. 1197, 401-416. doi:10.1016/j.molstruc. 2019.07.064

Botha, C., Kuntz, J.-F., Moire, C., Farcet, C., Pfukwa, H., and Pasch, H. (2018). Molar Mass Analysis of Hydrophobically Modified Hyaluronic Acid by SECMALLS: Facing the Challenges of Amphiphilic Biomacromolecules. Macromol. Chem. Phys. 219, 1800233. doi:10.1002/macp.201800233 
Bothner, H., Waaler, T., and Wik, O. (1988). Limiting Viscosity Number and Weight Average Molecular Weight of Hyaluronate Samples Produced by Heat Degradation. Int. J. Biol. Macromol. 10, 287-291. doi:10.1016/0141-8130(88) 90006-2

Buffa, R., Odstrčilová, L., Šedová, P., Basarabová, I., Novotný, J., and Velebný, V. (2018). Conjugates of Modified Hyaluronic Acid with Amino Compounds for Biomedical Applications. Carbohydr. Polym. 189, 273-279. doi:10.1016/j. carbpol.2018.02.048

Bulpitt, P., and Aeschlimann, D. (1999). New Strategy for Chemical Modification of Hyaluronic Acid: Preparation of Functionalized Derivatives and Their Use in the Formation of Novel Biocompatible Hydrogels. J. Biomed. Mater. Res. 47, 152-169. doi:10.1002/(SICI) 1097-4636(199911)47:2<152:AID-JBM5>3.0.CO; 2-I

Burdick, J. A., Chung, C., Jia, X., Randolph, M. A., and Langer, R. (2005). Controlled Degradation and Mechanical Behavior of Photopolymerized Hyaluronic Acid Networks. Biomacromolecules 6, 386-391. doi:10.1021/ bm049508a

Burdick, J. A., and Prestwich, G. D. (2011). Hyaluronic Acid Hydrogels for Biomedical Applications. Adv. Mater. 23, H41-H56. doi:10.1002/adma. 201003963

Calles, J. A., Tártara, L. I., Lopez-García, A., Diebold, Y., Palma, S. D., and Vallés, E. M. (2013). Novel Bioadhesive Hyaluronan-Itaconic Acid Crosslinked Films for Ocular Therapy. Int. J. Pharmaceut. 455, 48-56. doi:10.1016/j.ijpharm.2013. 07.063

Campoccia, D., Doherty, P., Radice, M., Brun, P., Abatangelo, G., and Williams, D. F. (1998). Semisynthetic Resorbable Materials from Hyaluronan Esterification. Biomaterials 19, 2101-2127. doi:10.1016/S0142-9612(98)00042-8

Caputo, H. E., Straub, J. E., and Grinstaff, M. W. (2019). Design, Synthesis, and Biomedical Applications of Synthetic Sulphated Polysaccharides. Chem. Soc. Rev. 48, 2338-2365. doi:10.1039/C7CS00593H

Chang, W. H., Liu, P. Y., Lin, M. H., Lu, C. J., Chou, H. Y., Nian, C. Y., et al. (2021). Applications of Hyaluronic Acid in Ophthalmology and Contact Lenses. Molecules 26, 2485. doi:10.3390/molecules26092485

Chen, F., Kakizaki, I., Yamaguchi, M., Kojima, K., Takagaki, K., and Endo, M. (2009). Novel Products in Hyaluronan Digested by Bovine Testicular Hyaluronidase. Glycoconj. J., 26,559-566. doi:10.1007/s10719-0089200-2

Clauder, F., Moeller, S., Köhling, S., Bellmann-Sickert, K., Rademann, J., Schnabelrauch, M., et al. (2020). Peptide-mediated Surface Coating for the Release of Wound-Healing Cytokines. J. Tissue Eng. Regen. Med. 14, 1738-1748. doi:10.1002/term.3123

Collins, M. N., and Birkinshaw, C. (2007). Comparison of the Effectiveness of Four Different Crosslinking Agents with Hyaluronic Acid Hydrogel Films for TissueCulture Applications. J. Appl. Polym. Sci. 104, 3183-3191. doi:10.1002/app. 25993

Collins, M. N., and Birkinshaw, C. (2013). Hyaluronic Acid Based Scaffolds for Tissue Engineering-A Review. Carbohydr. Polym. 92, 1262-1279. doi:10.1016/ j.carbpol.2012.10.028

Cozíková, D., Sílová, T., Moravcová, V., Smejkalová, D., Pepeliaev, S., Velebny, V., et al. (2017). Preparation and Extensive Characterization of Hyaluronan with Narrow Molecular Weight Distribution. Carbohydr. Polym. 160, 134-142. doi:10.1016/j.carbpol.2016.12.045

Crescenzi, V., Francescangeli, A., Renier, D., and Bellini, D. (2002a). New CrossLinked and Sulfated Derivatives of Partially Deacetylated Hyaluronan: Synthesis and Preliminary Characterization. Biopolymers 64, 86-94. doi:10. 1002/bip.10131

Crescenzi, V., Francescangeli, A., Renier, D., and Bellini, D. (2001). New Hyaluronan Chemical Derivatives. Regioselectively C(6) Oxidized Products. Macromolecules 34, 6367-6372. doi:10.1021/ma0102363

Crescenzi, V., Francescangeli, A., Segre, A. L., Capitani, D., Mannina, L., Renier, D., et al. (2002b). NMR Structural Study of Hydrogels Based on Partially Deacetylated Hyaluronan. Macromol. Biosci. 2, 272-279. doi:10.1002/16165195(200208)2:6<272:AID-MABI272>3.0.CO;2-V

Cyphert, J. M., Trempus, C. S., and Garantziotis, S. (2015). Size Matters: Molecular Weight Specificity of Hyaluronan Effects in Cell Biology. Int. J. Cel. Biol. 2015, 1-8. doi:10.1155/2015/563818

Dahl, L. B., Laurent, T. C., and Smedsrod, B. (1988). Preparation of Biologically Intact Radioiodinated Hyaluronan of High Specific Radioactivity: Coupling of
${ }^{125} 1$-Tyramine-Cellobiose to Amino Groups after Partial N-Deacetylation. Analyt. Biochem. 175, 397-407. doi:10.1016/0003-2697(88)90563-5

D’Amora, U., Ronca, A. A., Raucci, M. G., Dozio, S. M., Lin, H. H., Fan, Y. Y., et al. (2019). In Situ sol-gel Synthesis of Hyaluronan Derivatives Bio-Nanocomposite Hydrogels. Regen. Biomater. 6, 249-258. doi:10.1093/rb/rbz029

De Boulle, K., Glogau, R., Kono, T., Nathan, M., Tezel, A., Roca-Martinez, J. X., et al. (2013). A Review of the Metabolism of 1,4-Butanediol Diglycidyl Ether-Crosslinked Hyaluronic Acid Dermal Fillers. Dermatol. Surg. 39, 1758-1766. doi:10.1111/dsu.12301

DeAngelis, P. L. (2012). Glycosaminoglycan Polysaccharide Biosynthesis and Production: Today and Tomorrow. Appl. Microbiol. Biotechnol. 94, 295-305. doi:10.1007/s00253-011-3801-6

DeAngelis, P. L., Liu, J., and Linhardt, R. J. (2013). Chemoenzymatic Synthesis of Glycosaminoglycans: Re-creating, Re-modeling and Re-designing Nature's Longest or Most Complex Carbohydrate Chains. Glycobiology 23, 764-777. doi:10.1093/glycob/cwt016

D'Este, M., Eglina, D., and Alini, M. (2014). A Systematic Analysis of DMTMM vs EDC/NHS for Ligation of Amines to Hyaluronan in Water. Carbohydr. Polym. 108, 239-246. doi:10.1016/j.carbpol.2014.02.070

D'Este, M., Alini, M., and Eglin, D. (2012). Single Step Synthesis and Characterization of Thermoresponsive Hyaluronan Hydrogels. Carbohydr. Polym. 90, 1378-1385. doi:10.1016/j.carbpol.2012.07.007

Dicker, K. T., Gurski, L. A., Pradhan-Bhatt, S., Witt, R. L., Farach-Carson, M. C., and Jia, X. (2014). Hyaluronan: A Simple Polysaccharide with Diverse Biological Functions. Acta Biomater. 10, 1558-1570. doi:10.1016/j.copbio. 2017.12.018

Dovedytis, M., Liu, Z. J., and Bartlett, S. (2020). Hyaluronic Acid and its Biomedical Applications: A Review. Engin. Regen. 1, 102-113. doi:10.1016/j.engreg.2020. 10.001

Dreaden, E. C., Morton, S. W., Shopsowitz, K. E., Choi, J. H., Deng, Z. J., Cho, N. J., et al. (2014). Bimodal Tumor-Targeting from Microenvironment Responsive Hyaluronan Layer-By-Layer (LbL) Nanoparticles. ACS Nano 8 (8), 8374-8382. doi:10.1021/nn502861t

Duan, J., and Kasper, D. L. (2011). Oxidative Depolymerization of Polysaccharides by Reactive Oxygen/nitrogen Species. Glycobiology 21, 401-409. doi:10.1093/ glycob/cwq171

Dulong, V., Lack, S., Le Cerf, D., Picton, L., Vannier, J. P., and Muller, G. (2004). Hyaluronan-based Hydrogels Particles Prepared by Crosslinking with Trisodium Trimetaphosphate. Synthesis and Characterization. Carbohydr. Polym. 57, 1-6. doi:10.1016/j.carbpol.2003.12.006

Durana, R., Lacik, I., Paulovicova, E., and Bystricky, S. (2006). Functionalization of Mannans from Pathogenic Yeasts by Different Means of Oxidations Preparation of Precursors for Conjugation Reactions with Respect to Preservation of Immunological Properties. Carbohydr. Polym. 63, 72-81. doi:10.1016/j.carbpol.2005.08.003

Eenschooten, C., Guillaumie, F., Kontogeorgis, G. M., Stenby, E. H., and SchwachAbdellaoui, K. (2010). Preparation and Structural Characterisation of Novel and Versatile Amphiphilic Octenyl Succinic Anhydride-Modified Hyaluronic Acid Derivatives. Carbohydr. Polym. 79, 597-605. doi:10.1016/j.carbpol.2009. 09.011

Eng, D., Caplan, M., Preul, M., and Panitch, A. (2010). Hyaluronan Scaffolds: a Balance between Backbone Functionalization and Bioactivity. Acta Biomater. 6 (7), 2407-2414. doi:10.1016/j.actbio.2009.12.049

Fallacara, A., Baldini, E., Manfredini, S., and Vertuani, S. (2018). Hyaluronic Acid in the Third Millennium. Polymers 10, 701. doi:10.3390/polym10070701

Fallacara, A., Manfredini, S., Durini, E., and Vertuani, S. (2017). Hyaluronic Acid Fillers in Soft Tissue Regeneration. Facial Plast. Surg. 33, 87-96. doi:10.1055/s0036-1597685

Faust, H. J., Sommerfeld, S. D., Rathod, S., Rittenbach, A., Ray Banerjee, S., Tsui, B. M. W., et al. (2018). A Hyaluronic Acid Binding Peptide-Polymer System for Treating Osteoarthritis. Biomaterials 183, 93-101. doi:10.1016/j.biomaterials. 2018.08.045

Ferguson, E. L., Alshame, A. M., and Thomas, D. W. (2010). Evaluation of Hyaluronic Acid-Protein Conjugates for Polymer Masked-Unmasked Protein Therapy. Int. J. Pharm. 402 (1-2), 95-102. doi:10.1016/j.ijpharm. 2010.09.029

Fittolani, G., Tyrikos-Ergas, T., Vargová, D., Chaube, M. A., and Delbianco, M. (2021). Progress and Challenges in the Synthesis of Sequence Controlled 
Polysaccharides. Beilstein J. Org. Chem. 17, 1981-2025. doi:10.3762/bjoc. 17.129

Fraser, J. R. E., Laurent, T. C., and Laurent, U. B. G. (1997). Hyaluronan: its Nature, Distribution, Functions and Turnover. J. Intern. Med. 242, 27-33. doi:10.1046/j. 1365-2796.1997.00170.x

Gebe, J. A., Yadava, K., Ruppert, S. M., Marshall, P., Hill, P., Falk, B. A., et al. (2017). Modified High-Molecular-Weight Hyaluronan Promotes Allergen-specific Immune Tolerance. Am. J. Respir. Cel. Mol. Biol. 56, 109-120. doi:10.1165/ rcmb.2016-0111OC

Gligorovski, S., Strekowski, R., Barbati, S., and Vione, D. (2015). Environmental Implications of Hydroxyl Radicals $(\bullet \mathrm{OH})$. Chem. Rev. 115, 13051-13092. doi:10.1021/cr500310b

Griesser, J., Hetényi, G., and Bernkop-Schnürch, A. (2018). Thiolated Hyaluronic Acid as Versatile Mucoadhesive Polymer: From the Chemistry behind to Product Developments-What Are the Capabilities. Polymers 10, 243. doi:10.3390/polym10030243

Gronbach, M., Mitrach, F., Lidzba, V., Müller, B., Möller, S., Rother, S., et al. (2020). Scavenging of Dickkopf-1 by Macromer-Based Biomaterials Covalently Decorated with Sulphated Hyaluronan Displays Pro-osteogenic Effects. Acta Biomater. 114, 76-89. doi:10.1016/j.actbio.2020.07.017

Grosskopf, H., Vogel, S., Mueller, C. D., Köhling, S., Duerig, J.-N., Moeller, S., et al. (2021). Identification of Intracellular Glycosaminoglycan-Interaction Proteins by Affinity Purification Mass Spectrometry. Biol. Chem. 402, 1427-1440. doi:10. 1515/hsz-2021-0167

Hascall, V., and Esko, J. D. (2009). "Hyaluronan," in Essentials of Glycobiology. Editors A. Varki, R.D. Cummings, J.D. Esko, H.H. Freeze, P. Stanley, C.R. Bertozzi, et al. (Cold Cold Spring Harbor: Spring Harbor Laboratory Press), 219-227.

Heatley, F., and Scott, J. E. (1988). A Water Molecule Participates in the Secondary Structure of Hyaluronan. Biochem. J. 254, 489-493. doi:10.1042/bj2540489

Heinze, T., El Seoud, O. A., and Koschella, A. (2018). "Etherification of Cellulose," in Cellulose Derivatives: Synthesis, Structure, and Properties. Editors Heinze, T., El Seoud, O. A, and Koschella, A. (Cham: Springer). p. 293-427.

Heinze, T., and Liebert, T. (2001). Unconventional Methods in Cellulose Functionalization. Progr. Polym. Sci. 26, 1689-1762. doi:10.1016/S00796700(01)00022-3

Henrotin, Y., Raman, R., Richette, P., Bard, H., Jerosch, J., Conrozier, T., et al. (2015). Consensus Statement on Viscosupplementation with Hyaluronic Acid for the Management of Osteoarthritis. Semin. Arthritis Rheum. 45, 140-149. doi:10.1016/j.semarthrit.2015.04.011

Highley, C. B., Prestwich, G. D., and Burdick, J. A. (2016). Recent Advances in Hyaluronic Acid Hydrogels for Biomedical Applications. Curr. Opin. Biotechnol. 40, 35-40. doi:10.1016/j.copbio.2016.02.008

Hintze, V., Miron, A., Moeller, S., Schnabelrauch, M., Wiesmann, H. P., Worch, H., et al. (2012). Sulfated Hyaluronan and Chondroitin Sulfate Derivatives Interact Differently with Human Transforming Growth Factor-Beta 1 (TGF-Beta 1). Acta Biomater. 8 (6), 2144-2152. doi:10.1016/j.actbio.2012.03.021

Hintze, V., Moeller, S., Schnabelrauch, M., Bierbaum, S., Viola, M., Worch, H., et al. (2009). Modifications of Hyaluronan Influence the Interaction with Human Bone Morphogenetic Protein-4 (hBMP-4). Biomacromolecules 10, 3290-3297. doi:10.1021/bm9008827

Hintze, V., Samsonov, S. A., Anselmi, M., Moeller, S., Becher, J., Schnabelrauch, M., et al. (2014). Sulfated Glycosaminoglycans Exploit the Conformational Plasticity of Bone Morphogenetic Protein-2 (BMP-2) and Alter the Interaction Profile with its Receptor. Biomacromolecules 15 (8), 3083-3092. doi:10.1021/bm5006855

Huerta Angeles, G., and Nesporova, K. (2021). Hyaluronan and its Derivatives for Ophthalmology: Recent Advances and Future Perspectives. Carbohydr. Polym. 259, 117697. doi:10.1016/j.carbpol.2021.117697

Huerta-Angeles, G., Brandejsová, M., Kulhánek, J., Pavlík, V., Šmejkalová, D., Vágnerová, H., et al. (2016). Linolenic Acid Grafted Hyaluronan: Process Development, Structural Characterization, Biological Assessing, and Stability Studies. Carbohydr. Polym. 152, 815-824. doi:10.1016/j.carbpol.2016.07.030

Huerta-Angeles, G., Bobek, M., Príkopová, E., Smejkalová, D., and Velebny, V. (2014). Novel Synthetic Method for the Preparation of Amphiphilic Hyaluronan by Means of Aliphatic Aromatic Anhydrides. Carbohydr. Polym. 111, 883-891. doi:10.1016/j.carbpol.2014.05.035
Huerta-Angeles, G., Brandejsová, M., Nigmatullin, R., Kopecká, K., Vágnerová, H., Smejkalová, D., et al. (2017). Synthesis of Graft Copolymers Based on Hyaluronan and Poly(3-Hydroxyalkanoates). Carbohydr. Polym. 171, 220-228. doi:10.1016/j.carbpol.2017.05.011

Huin-Amargier, C., Marchal, P., Payan, E., Netter, P., and Dellacherie, E. (2005). New Physically and Chemically Crosslinked Hyaluronate (HA)-based Hydrogels for Cartilage Repair. J. Biomed. Mater. Res. 76A, 416-424. doi:10. 1002/jbm.a.30536

Jiang, B., Drouet, E., Milas, M., and Rinaudo, M. (2000). Study on TEMPOMediated Selective Oxidation of Hyaluronan and the Effects of Salt on the Reaction Kinetics. Carbohydr. Res. 327, 455-461. doi:10.1016/S0008-6215(00) 00059-8

Jin, R., Moreira Teixeira, L. S., Krouwels, A., Dijkstra, P. J., van Blitterswijk, C. A., Karperien, M., et al. (2010). Synthesis and Characterization of Hyaluronic Acid-Poly(ethylene Glycol) Hydrogels via Michael Addition: An Injectable Biomaterial for Cartilage Repair. Acta Biomater. 6, 1968-1977. doi:10.1016/j. actbio.2009.12.024

Jouon, N., Rinaudo, M., Milas, M., and Desbrihes, J. (1995). Hydration of Hyaluronic Acid as a Function of the Counterion Type and Relative Humidity. Carbohydr. Polym. 26, 69-73. doi:10.1016/0144-8617(95)98837-7

Kafedjiiski, K., Jetti, R. K. R., Foger, F., Hoyer, H., Werle, H., Hoffer, M., et al. (2007). Synthesis and In Vitro Evaluation of Thiolated Hyaluronic Acid for Mucoadhesive Drug Delivery. Int. J. Pharmaceut. 343, 48-58. doi:10.1016/j. ijpharm.2007.04.019

Kawaguchi, Y., Matsukawa, K., Gama, Y., and Ishigami, Y. (1992). The Effects of Polysaccharide Chain-Length in Coating Liposomes with Partial Palmitoyl Hyaluronates. Carbohydr. Polym. 18, 139-142. doi:10.1016/0144-8617(92) 90136-E

Kawaguchi, Y., Matsukawa, K., and Ishigami, Y. (1995). The Relation between the Adsorption Behavior at the Interface and the Conformational Changes in Hyaluronates Partially Modified with Various Acyl Chains. Carbohydr. Polym. 26, 149-154. doi:10.1016/0144-8617(94)00089-C

Kheirabadi, M., Shi, L., Bagheri, R., Kabiri, K., Hilborn, J., and Ossipov, D. A. (2015). In Situ forming Interpenetrating Hydrogels of Hyaluronic Acid Hybridized with Iron Oxide Nanoparticles. Biomater. Sci. 3, 1466-1474. doi:10.1039/C5BM00150A

Khunmanee, S., Jeong, Y., and Park, H. (2017). Crosslinking Method of Hyaluronic-Based Hydrogel for Biomedical Applications. J. Tiss. Eng. 8, 1-16. doi:10.1177/2041731417726464

Kim, C.-H., and Kim, J.-I. (2011). "Deacetylation Hydrolase of Hyaluronic Acid, Hyaluronic Acid Deacetylated by Same and Derivative Thereof". U.S. Patent 13/ 703,619.

Knopf-Marques, H., Pravda, M., Wolfova, L., Velebny, V., Schaaf, P., Vrana, N. E., et al. (2016). Hyaluronic Acid and its Derivatives in Coating and Delivery Systems: Applications in Tissue Engineering, Regenerative Medicine and Immunomodulation. Adv. Healthc. Mater. 5, 2841-2855. doi:10.1002/adhm. 201600316

Kocourková, K., Musilová, L., Smolka, P., Mráček, A., Humenik, M., and Minařík, A. (2021). Factors Determining Self-Assembly of Hyaluronan. Carbohydr. Polym. 254, 117307. doi:10.1016/j.carbpol.2020.117307

Koehler, L., Samsonov, S., Rother, S., Vogel, S., Köhling, S., Moeller, S., et al. (2017) Sulfated Hyaluronan Derivatives Modulate TGF- $\beta 1$ :Receptor Complex Formation: Possible Consequences for TGF-B1 Signaling. Sci. Rep. 7, 1210. doi:10.1038/s41598-017-01264-8

Koehling, S., Kunze, G., Lemmnitzer, K., Bermudez, M., Wolber, G., Schiller, J., et al. (2016). Chemoenzymatic Synthesis of Nonasulfated Tetrahyaluronan with a Paramagnetic Tag for Studying its Complex with Interleukin-10. Chem. Eur. J. 22, 563-5574. doi:10.1002/chem.201504459

Kotla, N. G., Bonam, S. R., Rasala, S., Wankar, J., Bohara, R. A., Bayry, J., et al. (2021). Recent Advances and Prospects of Hyaluronan as a Multifunctional Therapeutic System. J. Controlled. Rel. 336, 598-620. doi:10.1016/j.jconrel.2021. 07.002

Kristiansen, K. A., Potthast, A., and Christensen, B. E. (2010). Periodate Oxidation of Polysaccharides for Modification of Chemical and Physical Properties. Carbohydr. Res. 345, 1264-1271. doi:10.1016/j.carres.2010.02.011

Krupkova, O., Greutert, H., Boos, N., Lemcke, J., Liebscher, T., and Wuertz-Kozak, K. (2020). Expression and Activity of Hyaluronidases HYAL-1, HYAL-2 and 
HYAL-3 in the Human Intervertebral Disc. Eur. Spine J. 29, 605-615. doi:10. 1007/s00586-019-06227-3

Kunze, R., Rösler, M., Möller, S., Schnabelrauch, M., Riemer, T., Hempel, U., et al. (2010). Sulfated Hyaluronan Derivatives Reduce the Proliferation Rate of Primary Rat Calvarial Osteoblasts. Glycoconj. J. 27, 151-158. doi:10.1007/ s10719-009-9270-9

Kwag, D. S., Oh, K. T., and Lee, E. S. (2014). Facile Synthesis of Multilayered Polysaccharidic Vesicles. J. Controlled Rel. 187, 83-90. doi:10.1016/j.jconrel. 2014.05.032

La Gatta, A., Stellavato, A., Vassallo, V., Di Meo, C., Toro, G., Iolascon, G., et al. (2021). Hyaluronan and Derivatives: An In Vitro Multilevel Assessment of Their Potential in Viscosupplementation. Polymers 13, 3208. doi:10.3390/ polym 13193208

Lapcik, L., Jr., Benesova, K., Lapcik, L., De Smedt, S., and Lapcikova, B. (2010). Chem. Modification Hyaluronic Acid: Alkylation. Int. J. Polym. Anal. Charact. 15, 486-496. doi:10.1080/1023666X.2010.520904

Laurent, T. C., Laurent, U. B. G., and Fraser, J. R. E. (1996). The Structure and Function of Hyaluronan: An Overview Immunol. Cell Biol. 74, A1-A7. doi:10. 1038/icb.1996.32

Lee, M. Y., Yang, J. A., Jung, H. S., Beack, S., Choi, J. E., Hur, W., et al. (2012). Hyaluronic Acid-Gold Nanoparticle/interferon a Complex for Targeted Treatment of Hepatitis C Virus Infection. ACS Nano 6, 9522-9531. doi:10. $1021 / \mathrm{nn} 302538 \mathrm{y}$

Leone, G., Consumi, M., Lamponi, S., and Magnani, A. (2012). New Hyaluroran Derivative with Prolonged Half-Life for Ophthalmogical Formulation. Carbohydr. Polym. 88, 799-808. doi:10.1016/j.carbpol.2011.12.047

Litwiniuk, M., Krejner, A., and Grzela, T. (2016). Hyaluronic Acid in Inflammation and Tissue Regeneration. Wounds 28, 78-88.

Loebel, C., D'Estea, M., Alinia, M., Zenobi-Wong, M., and Eglin, D. (2015). Precise Tailoring of Tyramine-Based Hyaluronan Hydrogel Properties Using DMTMM Conjugation. Carbohydr. Polym. 115, 325-333. doi:10.1016/j. carbpol.2014.08.097

Lowry, K. M., and Beavers, E. M. (1994). Thermal Stabilitv of Sodium Hyaluronate in Aqueous Solution. J. Biomed. Mater. Res. 28, 1239-1244. doi:10.1002/jbm. 820281014

Magnani, A., Albanese, A., Lamponi, S., and Barbucci, R. (1996). Blood-interaction Performance of Differently Sulphated Hyaluronic Acids. Thromb. Res. 81, 383-395. doi:10.1016/0049-3848(96)00009-6

Magnani, A., Lamponi, S., Rappuoli, R., and Barbucci, R. (1998). Sulphated Hyaluronic Acids: a Chemical and Biological Characterization. Polym. Int. 46, 225-240. doi:10.1002/(SICI)1097-0126(199807)46:3<225:AID-PI45>3.0. CO;2-I

Magnani, A., Rappuoli, R., Lamponi, S., and Barbucci, R. (2000). Novel Polysaccharide Hydrogels: Characterization and Properties. Polym. Adv. Technol. 11, 488-495. doi:10.1002/1099-1581(200008/12)11:8/12<488:AIDPAT995 >3.0.CO;2-5

Manfrão-Netto, J. H. C., Queiroz, E. B., de Oliveira Junqueira, A. C., Gomes, A. M. V., Gusmão de Morais, D., Costa Paes, H., et al. (2021). Genetic Strategies for Improving Hyaluronic Acid Production in Recombinant Bacterial Culture. J. Appl. Microbiol. in press. doi:10.1111/jam.15242

Mende, M., Bednarek, C., Wawryszyn, M., Sauter, P., Biskup, M. B., Schepers, U., et al. (2016). Chemical Synthesis of Glycosaminoglycans. Chem. Rev. 116, 8193-8255. doi:10.1021/acs.chemrev.6b00010

Mergy, J., Fournier, A., Hachet, E., and Auzely-Velty, R. (2012). Modification of Polysaccharides via Thiol-Ene Chemistry: A Versatile Route to Functional Biomaterials. J. Polym. Sci. Part. A: Polym. Chem. 50, 4019-4028. doi:10.1002/ pola.26201

Mero, A., and Campisi, M. (2014). Hyaluronic Acid Bioconjugates for the Delivery of Bioactive Molecules. Polymers 6, 346-369. doi:10.3390/polym6020346

Minsky, B. B., Antoni, C. H., and Boehm, H. (2016). Controlled Immobilization Strategies to Probe Short Hyaluronan-Protein Interactions. Sci. Rep. 6, 21608. doi:10.1038/srep21608

Mlbochová, P., Hájková, V., Steiner, B., Bystrický, S., Koón, M., Medová, M., et al. (2007). Preparation and Characterization of Biodegradable Alkylether Derivatives of Hyaluronan. Carbohydr. Polym. 69, 344-352. doi:10.1016/j. carbpol.2006.10.015

Moeller, S., Schmidtke, M., Weiss, D., Schiller, J., Pawlik, K., Wutzler, P., et al. (2012). Synthesis and Antiherpetic Activity of Carboxymethylated and Sulfated
Hyaluronan Derivatives. Carbohydr. Polym. 90, 608-615. doi:10.1016/j.carbpol. 2012.05.085

Moeller, S., Weisser, J., Bischoff, S., and Schnabelrauch, M. (2007). Dextran and Hyaluronan Methacrylate Based Hydrogels as Matrices for Soft Tissue Reconstruction. Biomol. Eng. 24, 496-504. doi:10.1016/j.bioeng.2007.08.014

Moradali, M. F., and Rehm, B. H. A. (2020). Bacterial Biopolymers: from Pathogenesis to Advanced Materials. Nat. Rev. 18, 195-210. doi:10.1038/ s41579-019-0313-3

Nagira, T., Nagahata-Ishiguroa, M., and Tsuchiya, T. (2007). Effects of Sulfated Hyaluronan on Keratinocyte Differentiation and Wnt and Notch Gene Expression. Biomaterials 28, 844-850. doi:10.1016/j.biomaterials.2006.09.041

Nejadnik, M. R., Yang, X., Bongio, M., Alghamdi, H. S., van den Beucken, J. J., Huysmans, M. C., et al. (2014). Self-healing Hybrid Nanocomposites Consisting of Bisphosphonated Hyaluronan and Calcium Phosphate Nanoparticles. Biomaterials 35, 6918-6929. doi:10.1016/j.biomaterials.2014.05.003

Ni, Y., Tang, Z., Cao, W., Lin, H., Fan, Y., and Guo, L. (2015). Tough and elastic hydrogel of hyaluronic acid and chondroitin sulfate as potential cell scaffold materials. Int. J. Biol. Macromol. 74, 367-375. doi:10.1016/j.ijbiomac.2014. 10.058

Nicholls, M., Manjoo, A., Shaw, P., Niazi, F., and Rosen, J. A. (2018). Comparison between Rheological Properties of Intra-articular Hyaluronic Acid Preparations and Reported Human Synovial Fluid. Adv. Ther. 35, 523-530. doi:10.1007/ s12325-018-0688-y

Novoa-Carballal, R., and Müller, A. H. E. (2012). Synthesis of Polysaccharide-BPEG Block Copolymers by Oxime Click. Chem. Commun. 48, 3781-3783. doi:10.1039/c2cc30726j

Oelschlaeger, C., Bossler, F., and Willenbacher, N. (2016). Synthesis, Structural and Micromechanical Properties of 3D Hyaluronic Acid-Based Cryogel Scaffolds. Biomacromolecules 2016 (17), 580-589. doi:10.1021/acs.biomac. 5 b01529

Oh, E. J., Park, K., Kim, K. S., Kim, J., Yang, J.-A., Kong, J.-H., et al. (2010). Target Specific and Long-Acting Delivery of Protein, Peptide, and Nucleotide Therapeutics Using Hyaluronic Acid Derivatives. J. Controlled Rel. 141, 2-12. doi:10.1016/j.jconrel.2009.09.010

Ossipov, D. A., Piskounova, S., Varghese, O. P., and Hilborn, J. (2010). Functionalization of Hyaluronic Acid with Chemoselective Groups via a Disulfide-Based Protection Strategy for In Situ Formation of Mechanically Stable Hydrogels. Biomacromolecules 11, 2247-2254. doi:10.1021/ bm1007986

Palhares, L. C. G. F., London, J. A., Kozlowski, A. M., Esposito, E., Chavante, S. F., Ni, M., et al. (2021). Chemical Modification of Glycosaminoglycan Polysaccharides. Molecules 26, 5211. doi:10.3390/molecules 26175211

Peerboom, N., Block, S., Altgarde, N., Wahlsten, O., Moeller, S., Schnabelrauch, M., et al. (2017). Binding Kinetics and Lateral Mobility of HSV-1 on End-Grafted Sulfated Glycosaminoglycans. Biophysical J. 113, 1223-1234. doi:10.1016/j.bpj. 2017.06.028

Picotti, F., Fabbian, M., Gianni, R., Sechi, A., Stucchi, L., and Bosco, M. (2013). Hyaluronic Acid Lipoate: Synthesis and Physicochemical Properties. Carbohydr. Polym. 93, 273-278. doi:10.1016/j.carbpol.2012.04.009

Pierre, G., Punta, C., Delattre, C., Melone, L., Dubessay, P., Fiorati, A., et al. (2017). TEMPO-mediated Oxidation of Polysaccharides: An Ongoing Story. Carbohydr. Polym. 165, 71-85. doi:10.1016/j.carbpol.2017.02.028

Pomin, V. H., and Mulloy, B. (2018). Glycosaminoglycans and Proteoglycans. Pharmaceuticals 11, 27. doi:10.3390/ph11010027

Pravata, L., Braud, C., Boustta, M., El Ghzaoui, A., Tømmeraas, K., Guillaumie, F. et al. (2008). New Amphiphilic Lactic Acid Oligomer-Hyaluronan Conjugates: Synthesis and Physicochemical Characterization. Biomacromolecules 9, 340-348. doi:10.1021/bm700843m

Prestwich, G. D., Marecak, D. M., Marecek, J. F., Vercruysse, K. P., and Ziebell, M. R. (1998). Controlled Chemical Modification of Hyaluronic Acid: Synthesis, Applications, and Biodegradation of Hydrazide Derivatives. J. Controlled. Rel. 53, 93-103. doi:10.1016/S0168-3659(97)00242-3

Qin, X.-H., Gruber, P., Markovic, M., Plochberger, B., Klotzsch, E., Stampfl, et al. (2014). Enzymatic Synthesis of Hyaluronic Acid Vinyl Esters for Two-Photon Microfabrication of Biocompatible and Biodegradable Hydrogel Constructs. Polym. Chem. 5, 6523. doi:10.1039/c4py00792a

Rah, M. J. (2011). A Review of Hyaluronan and its Ophthalmic Applications. Optometry 82, 38-43. doi:10.1016/j.optm.2010.08.003 
Rother, S., Galiazzo, V. D., Kilian, D., Fiebig, K. M., Becher, J., Moeller, S., et al. (2017a). Hyaluronan/collagen Hydrogels with Sulfated Hyaluronan for Improved Repair of Vascularized Tissue Tune the Binding of Proteins and Promote Endothelial Cell Growth. Macromol. Biosci. 17, 1700154. doi:10.1002/mabi.201700154

Rother, S., Ruiz-Gómez, G., Koehler, L., Balamurugan, K., Fiebig, K. M., Galiazzo, V. D., et al. (2021). Hyaluronan/collagen Hydrogels with Sulfated Glycosaminoglycans Maintain VEGF $_{165}$ Activity and fine-tune Endothelial Cell Response. ACS Appl. Bio Mater. 4 (1), 494-506. doi:10.1021/acsabm.0c01001

Rother, S., Salbach-Hirsch, J., Moeller, S., Seemann, T., Schnabelrauch, M., Hofbauer, L. C., et al. (2015). Bioinspired Collagen/GlycosaminoglycanBased Cellular Microenvironments for Tuning Osteoclastogenesis. ACS Appl. Mater. Inter. 7, 23787-23797. doi:10.1021/acsami.5b08419

Rother, S., Samsonov, S. A., Hempel, U., Vogel, S., Moeller, S., Blaszkiewicz, J., et al. (2016b). Sulfated Hyaluronan Alters the Interaction Profile of TIMP-3 with the Endocytic Receptor LRP-1 Clusters II and IV and Increases the Extracellular TIMP-3 Level of Human Bone Marrow Stromal Cells. Biomacromolecules 17, 3252-3261. doi:10.1021/acs.biomac.6b00980

Rother, S., Samsonov, S. A., Hofmann, T., Blaszkiewicz, J., Köhling, S., Moeller, S., et al. (2016a). Structural and Functional Insights into the Interaction of Sulfated Glycosaminoglycans with Tissue Inhibitor of Metalloproteinase-3-A Possible Regulatory Role on Extracellular Matrix Homeostasis. Acta Biomater. 45, 143-154. doi:10.1016/j.actbio.2016.08.030

Rother, S., Samsonov, S. A., Moeller, S., Schnabelrauch, M., Rademann, J., Blaszkiewicz, J., et al. (2017b). Sulfated Hyaluronan Alters Endothelial Cell Activation In Vitro by Controlling the Biological Activity of the Angiogenic Factors Vascular Endothelial Growth Factor-A and Tissue Inhibitor of Metalloproteinase-3. ACS Appl. Mater. Inter. 9, 9539-9550. doi:10.1021/acsami.7b01300

Salbach-Hirsch, J., Samsonov, S. A., Hintze, V., Hofbauer, C., Picke, A. K., Rauner, M., et al. (2015). Structural and Functional Insights into SclerostinGlycosaminoglycan Interactions in Bone. Biomaterials 67, 335-345. doi:10. 1016/j.biomaterials.2015.07.021

Salbach-Hirsch, J., Kraemer, J., Rauner, M., Samsonov, S., Pisabarro, M. T., Moeller, S., et al. (2013). The Promotion of Osteoclastogenesis by Sulfated Hyaluronan through Interference with Osteoprotegerin and Receptor Activator of NF-Kb Ligand/ osteoprotegerin Complex Formation. Biomaterials 34, 7653-7661. doi:10.1016/j. biomaterials.2013.06.053

Sanfilippo, V., Caruso, V. C. L., Cucci, L. M., Inturri, R., Vaccaro, S., and Satriano, C. (2020). Hyaluronan-Metal Gold Nanoparticle Hybrids for Targeted Tumor Cell Therapy. Int. J. Mol. Sci. 21, 3085. doi:10.3390/ijms21093085

Satoh, T., Nagahata, M., Teramoto, A., Hatimori, A., Abe, K., and Im, S. S. (2004). The Basic Research on Physiological Property of Functionalized Hyaluronan-I. Effect of Hyaluronanand Sulfated Hyaluronan on Cell Proliferation of Human Epidermal Keratinocytes. Polym. Adv. Technol. 15, 329-334. doi:10.1002/pat.468

Schanté, C. E., Zuber, G., Herlin, C., and Vandamme, T. F. (2011). Chemical Modifications of Hyaluronic Acid for the Synthesis of Derivatives for a Broad Range of Biomedical Applications. Carbohydr. Polym. 85, 469-489. doi:10. 1016/j.carbpol.2011.03.019

Scharnweber, D., Hübner, L., Rother, S., Hempel, U., Anderegg, U., Samsonov, S. A., et al. (2015). Glycosaminoglycan Derivatives: Promising Candidates for the Design of Functional Biomaterials. J. Mater. Sci. Mater. Med. 26, 232. doi:10. 1007/s10856-015-5563-7

Schnabelrauch, M., Scharnweber, D., and Schiller, J. J. (2013). Sulfated Glycosaminoglycans as Promising Artificial Extracellular Matrix Components to Improve the Regeneration of Tissues. Curr. Med. Chem. 20, 2501-2523. doi:10.2174/0929867311320200001

Schnabelrauch, M., Schiller, J., Möller, S., Scharnweber, D., and Vera Hintze, V. (2021). Chemically Modified Glycosaminoglycan Derivatives as Building Blocks for Biomaterial Coatings and Hydrogels. Biol. Chem. 402, 1385-1395. doi:10.1515/hsz-2021-0171

Scott, J. E. (1962). The Precipitation of Polyanions by Long-Chain Aliphatic Ammonium Salts. 6. The Affinity of Substituted Ammonium Cations for the Anionic Groups of Some Biological Polymers. Biochem. J. 84, 270-275. doi:10.1042/bj0840270

Scott, J. E., Cummings, C., Brass, A., and Chen, Y. (1991). Secondary and Tertiary Structures of Hyaluronan in Aqueous Solution, Investigated by Rotary Shadowing-Electron Microscopy and Computer Simulation. Hyaluronan Is a
Very Efficient Network-Forming Polymer. Biochem. J. 274, 699-705. doi:10. 1042/bj2740699

Scott, J. E. (1992). Supramolecular Organization of Extracellular Matrix Glycosaminoglycans, In Vitro and in the Tissues. FASEB J. 6, 2639-2645. doi:10.1096/fasebj.6.9.1612287

Sedláček, J., Hermannová, M., Šatínskýa, D., and Velebný, V. (2020). Current Analytical Methods for the Characterization of N-Deacetylated Hyaluronan: A Critical Review. Carbohydr. Polym. 249, 116720. doi:10.1016/j.carbpol.2020.116720

Šedová, P., Buffa, R., Kettou, S., Huerta-Angeles, G., Hermannová, M., Leierová, V., et al. (2013). Preparation of Hyaluronan Polyaldehyde-A Precursor of Biopolymer Conjugates. Carbohydr. Res. 371, 8-15. doi:10.1016/j.carres.2013.01.025

Seidlits, S. K., Khaing, Z. Z., Petersen, R. R., Nickels, J. D., Vanscoy, J. E., Shear, J. B., et al. (2010). The Effects of Hyaluronic Acid Hydrogels with Tunable Mechanical Properties on Neural Progenitor Cell Differentiation. Biomaterials 31, 3930-3940. doi:10.1016/j. biomaterials.2010.01.125

Serban, M. A., and Prestwich, G. D. (2008). Synthesis of Hyaluronan Haloacetates and Biology of Novel Cross-linker-free Synthetic Extracellular Matrix Hydrogels. Biomacromolecules 8, 2821-2828. doi:10.1021/bm700595s

Serban, M. A., Yang, G., and Prestwich, G. D. (2008). Synthesis, Characterization and Chondroprotective Properties of a Hyaluronan Thioethyl Ether Derivative. Biomaterials 29, 1388-1399. doi:10.1016/j. biomaterials.2007.12.006

Shan, J., Böck, T., Keller, T., Forster, L., Blunk, T., Groll, J., et al. (2021). TEMPO/ TCC as a Chemo Selective Alternative for the Oxidation of Hyaluronic Acid. Molecules 26, 5963. doi:10.3390/molecules26195963

Shimojo, A. A. M., Pires, A. M. B., Lichy, R., and Santana, M. H. A. (2015). The Performance of Crosslinking with Divinyl Sulfone as Controlled by the Interplay between the Chemical Modification and Conformation of Hyaluronic Acid. J. Braz. Chem. Soc. 26, 506-512. doi:10.5935/0103-5053.20150003

Shu, X. Z., Liu, Y., Luo, Y., Roberts, M. C., and Prestwich, G. D. (2002). Disulfide Cross-Linked Hyaluronan Hydrogels. Biomacromolecules 3, 1304-1311. doi:10. 1021/bm025603c

Smeds, K. A., Pfister-Serres, A., Miki, D., Dastgheib, K., Inoue, M., Hatchell, D. L., et al. (2001). Photocrosslinkable Polysaccharides for In Situ Hydrogel Formation. J. Biomed. Mater. Res. 54, 115-121. doi:10.1002/10974636(200101)54:1<115:AID-JBM14>3.0.CO;2-Q

Smejkalová, D., Hermannová, M., Buffa, R., Cozíková, D., Vistejnová, L., Matulková, Z., et al. (2012a). Structural Characterization and Biological Properties of Degradation Byproducts from Hyaluronan after Acid Hydrolysis. Carbohydr. Polym. 88, 1425-1434. doi:10.1016/j.carbpol.2012.02.031

Smejkalová, D., Hermannová, M., Suláková, R., Prusová, A., Kucerík, J., and Velebny, V. (2012b). Structural and Conformational Differences of Acylated Hyaluronan Modified in Protic and Aprotic Solvent System. Carbohydr. Polym. 87, 1460-1465. doi:10.1016/j.carbpol.2011.09.057

Smejkalová, D., Nešporová, K., Huerta-Angeles, G., Syrovátka, J., Jirák, D., Gálisová, A., et al. (2014). Selective In Vitro Anticancer Effect of Superparamagnetic Iron Oxide Nanoparticles Loaded in Hyaluronan Polymeric Micelles. Biomacromolecules 15, 4012-4020. doi:10.1021/ bm501065q

Stellavato, A., Vassallo, V., La Gatta, A., Pirozzi, A. V. A., De Rosa, M., Balato, G., et al. (2019). Novel Hybrid Gels Made of High and Low Molecular Weight Hyaluronic Acid Induce Proliferation and Reduce Inflammation in an Osteoarthritis In Vitro Model Based on Human Synoviocytes and Chondrocytes. Biomed. Res. Int. 23, 4328219. doi:10. $1155 / 2019 / 4328219$

Stern, R. (2004). Hyaluronan Catabolism: a New Metabolic Pathway. Eur. J. Cel. Biol. 83, 317-325. doi:10.1078/0171-9335-00392

Stern, R., Asari, A. A., and Sugahara, K. N. (2006). Hyaluronan Fragments: an Information-Rich System. Eur. J. Cel. Biol. 85, 699-715. doi:10.1016/j.ejcb.2006. 05.009

Stern, R., Kogan, G., Jedrzejas, M. J., and Šoltés, L. (2007). The many Ways to Cleave Hyaluronan. Biotechnol. Adv. 25, 537-557. doi:10.1016/j.biotechadv. 2007.07.001

Tawada, A., Masa, T., Oonuki, Y., Watanabe, A., MatsuzakiY.and Asari, A. (2002). Large-scale Preparation, Purification, and Characterization of Hyaluronan Oligosaccharides from 4-mers to 52-mers. Glycobiology 12, 421-426. doi:10. 1093/glycob/cwf048 
Thakar, D., Migliorini, E., Coche-Guerente, L., Sadir, R., Lortat-Jacob, H., Boturyn, D., et al. (2014). A Quartz crystal Microbalance Method to Study the Terminal Functionalization of Glycosaminoglycans. Chem. Commun. 50, 15148-15151. doi:10.1039/c4cc06905f

Thönes, S., Rother, S., Wippold, T., Blaszkiewicz, J., Balamurugan, K., Moeller, S., et al. (2019). Hyaluronan/collagen Hydrogels Containing Sulfated Hyaluronan Improve Wound Healing by Sustained Release of Heparin-Binding EGF-like Growth Factor. Acta Biomater. 86, 135-147. doi:10.1016/j.actbio.2019.01.029

Townley, R. A., and Bülow, H. E. (2018). Deciphering Functional Glycosaminoglycan Motifs in Development. Curr. Opin. Struct. Biol. 50, 144-154. doi:10.1016/j.sbi.2018.03.011

Unnikandam Veettil, S. R., Hwang, D., Correia, J., Bartlett, M. D., and Schneider, I. C. (2021). Cancer Cell Migration in Collagen-Hyaluronan Composite Extracellular Matrices. Acta Biomater. 130, 183-198. doi:10.1016/j.actbio.2021.06.009

Valachová, K., and Šoltés, L. (2021). Hyaluronan as a Prominent Biomolecule with Numerous Applications in Medicine. Int. J. Mol. Sci. 22, 7077. doi:10.3390/ ijms 22137077

van der Smissen, A., Samsonov, S., Hintze, V., Scharnweber, D., Moeller, S., Schnabelrauch, M., et al. (2013). Artificial Extracellular Matrix Composed of Collagen I and Highly Sulfated Hyaluronan Interferes with TGF $\beta-1$ Signaling and Prevents TGF $\beta 1$-Induced Myofibroblast Differentiation. Acta Biomater. 9, 7775-7786. doi:10.1016/j.actbio.2013.04.023

Vasi, A.-M., Popa, M. I., Butnaru, M., Dodi, G., and Verestiuc, L. (2014). Chemical Functionalization of Hyaluronic Acid for Drug Delivery Applications. Mater. Sci. Eng. C 38, 177-185. doi:10.1016/j.msec.2014.01.052

Vigetti, D., Viola, M., Karousou, E., De Luca, G., and Passi, A. (2014). Metabolic Control of Hyaluronan Synthases. Matrix Biol. 35, 8-13. doi:10.1016/j.matbio. 2013.10.002

Wada, T., Chirachanchai, S., Izawa, N., Inaki, Y., and Takemoto, K. (1994). Synthesis and Properties of Hyaluronic Acid Conjugated Nucleic Acid Analogs-1: Synthesis of Deacetylhyaluronan and Introduction of Nucleic Acid Bases. J. Bioact. Compat. Polym. 9, 429-447. doi:10.1177/ 088391159400900405

Walvoort, M. T., Volbeda, A. G., Reintjens, N. R., van den Elst, H., Plante, O. J., Overkleeft, H. S., et al. (2012). Automated Solid-phase Synthesis of Hyaluronan Oligosaccharides. Org. Lett. 14, 3776-3779. doi:10.1021/ol301666n

Wang, J. K., Luo, B., Guneta, V., Li, L., Min Foo, S. E., Dai, Y., et al. (2017). Supercritical Carbon Dioxide Extracted Extracellular Matrix Material from Adipose Tissue. Mater. Sci. Engin. C 75, 349-358. doi:10.1016/j.msec.2017. 02.002

Williams, D. (2014). Essential Biomaterials Science. Cambridge: Cambridge University Press, 537-539.

Wyrwa, R., Schnabelrauch, M., and Becher, J. (2012). "Process for the Degradation of Polysaccharides Selected from the Groups of Substances of the Glycosaminoglycans and Derivatives Thereof and Alginates". German Patent No. 10, 2012,009,593.

Xu, Y., Wu, Y., Sun, P., Zhang, F., Linhardt, R. J., and Zhang, A. (2019). Chemically Modified Polysaccharides: Synthesis, Characterization, Structure Activity Relationships of Action. Int. J. Biol. Macromol. 132, 970-977. doi:10.1016/j. ijbiomac.2019.03.213

Xue, Y., Chen, H., Xu, C., Yu, D., Xu, H., and Hu, Y. (2020). Synthesis of Hyaluronic Acid Hydrogels by Crosslinking the Mixture of High-MolecularWeight Hyaluronic Acid and Low-Molecular-Weight Hyaluronic Acid with 1,4-butanediol Diglycidyl Ether. RSC Adv. 10, 7206-7213. doi:10.1039/ C9RA09271D

Yang, S., Guo, Z., Miao, F., Xue, Q., and Qin, S. (2010). The Hydroxyl Radical Scavenging Activity of Chitosan, Hyaluronan, Starch and Their
O-Carboxymethylated Derivatives. Carbohydr. Polym. 82, 1043-1045. doi:10. 1016/j.carbpol.2010.06.014

Yuan, H., Tank, M., Alsofyani, A., Shah, N., Talati, N., LoBello, J. C., et al. (2013). Molecular Mass Dependence of Hyaluronan Detection by sandwich ELISA-like Assay and Membrane Blotting Using Biotinylated Hyaluronan Binding Protein. Glycobiology 23, 1270-1280. doi:10.1093/glycob/cwt064

Yue, W. (2012). Preparation of Low-Molecular-Weight Hyaluronic Acid by Ozone Treatment. Carbohydr. Polym. 89, 709-712. doi:10.1016/j.carbpol. 2012.03.081

Yui, N., Okano, T., and Sakurai, Y. (1992). Inflammation Responsive Degradation of Crosslinked Hyaluronic Acid Gels. J. Controlled Rel. 22, 105-116. doi:10. 1016/0168-3659(92)90195-W

Zakrzewska, M. E., Bogel-Lukasik, E., and Bogel-Lukasik, R. (2010). Solubility of Carbohydrates in Ionic Liquids. Energy Fuels 24, 737-745. doi:10.1021/ ef $901215 \mathrm{~m}$

Zhang, M., and James, S. P. (2005a). Silylation of Hyaluronan to Improve Hydrophobicity and Reactivity for Improved Processing and Derivatization. Polymer 46, 3639-3648. doi:10.1016/j.polymer.2005.03.022

Zhang, M., and James, S. P. (2005b). Synthesis and Properties of Melt-Processable Hyaluronan Esters. J. Mater. Sci. Mater. Med. 40, 2937-2943. doi:10.1007/ s10853-005-2432-7

Zhang, R., Huang, Z. B., Xue, M. Y., Yang, J., and Tan, T. W. (2011). Detailed Characterization of an Injectable Hyaluronic Acid-Polyaspartylhydrazide Hydrogel for Protein Delivery. Carbohydr. Polym. 85, 717-725. doi:10.1016/ j.carbpol.2011.02.014

Zhang, W., Mu, H., Zhang, A., Cui, G., Chen, H., and Duan, J. (2013). A Decrease in Moisture Absorption-Retention Capacity of N-Deacetylation of Hyaluronic Acid. Glycoconj. J. 30, 577-583. doi:10.1007/s10719-0129457-3

Zhang, Y., Heher, P., Hilborn, J., Redl, H., and Ossipov, D. A. (2016). Hyaluronic Acid-Fibrin Interpenetrating Double Network Hydrogel Prepared In Situ by Orthogonal Disulfide Cross-Linking Reaction for Biomedical Applications. Acta Biomater. 38, 23-32. doi:10.1016/j.actbio.2016.04.041

Zhao, X. (2006). Synthesis and Characterization of a Novel Hyaluronic Acid Hydrogel. J. Biomater. Sci. Polym. 17, 419-433. doi:10.1163/156856206776374115

Zhou, S., and Huang, G. (2021). Preparation, Structure and Activity of Polysaccharide Phosphate Esters. Biomed. Pharmacotherap. 144, 112332. doi:10.1016/j.biopha.2021.112332

Conflict of Interest: The authors declare that the research was conducted in the absence of any commercial or financial relationships that could be construed as a potential conflict of interest.

Publisher's Note: All claims expressed in this article are solely those of the authors and do not necessarily represent those of their affiliated organizations, or those of the publisher, the editors and the reviewers. Any product that may be evaluated in this article, or claim that may be made by its manufacturer, is not guaranteed or endorsed by the publisher.

Copyright (c) 2022 Hintze, Schnabelrauch and Rother. This is an open-access article distributed under the terms of the Creative Commons Attribution License (CC BY). The use, distribution or reproduction in other forums is permitted, provided the original author(s) and the copyright owner(s) are credited and that the original publication in this journal is cited, in accordance with accepted academic practice. No use, distribution or reproduction is permitted which does not comply with these terms. 